\title{
Persistent shallow micro-seismicity at Llaima volcano, Chile, with implications for long-term monitoring
}

\author{
Oliver D. Lamb ${ }^{1, *}$, Jonathan M. Lees ${ }^{1}$, Luis Franco Marin ${ }^{2}$, Jonathan Lazo ${ }^{2,3}$ \\ Andrés Rivera $^{4}$, Michael J. Shore ${ }^{1}$, and Stephen J. Lee ${ }^{5}$ \\ ${ }^{1}$ Dept. of Earth, Marine and Environmental Sciences, University of North Carolina at Chapel Hill, Chapel Hill, NC, USA \\ 2 OVDAS-Sernageomin, Chilean Geological Survey, Chile \\ ${ }^{3}$ Dept. of Physical Sciences, University of La Frontera, Temuco, Chile \\ ${ }^{4}$ Dept. de Geografía, Universidad de Chile, Chile \\ ${ }^{5}$ U.S. Army Research Laboratory/Army Research Office, Research Triangle Park, NC, USA \\ *Correspondence to: O. D. Lamb, olamb@email.unc.edu
}

This pdf is a non-peer-reviewed preprint of the article submitted for review in Journal of Volcanology and Geothermal Research in October 2021. Subsequent versions of this manuscript will likely differ. If accepted, this pdf will be updated with a DOI of the final version. Feel free to contact any of the authors; we welcome any feedback.

\section{ABSTRACT}

Identifying the source mechanisms of low-frequency earthquakes at ice-covered volcanoes can be challenging due to overlapping characteristics of glacially and magmatically derived seismicity. Here we present an analysis of two months of seismic data from Llaima volcano, Chile, recorded by the permanent monitoring network in 2019. We find over 2,000 repeating low-frequency events split across 82 families, the largest of which contains over 200 events. Estimated locations for the largest families indicate shallow sources directly beneath or near the edge of glaciers around the summit vent. These low-frequency earthquakes are part of an annual cycle in activity at the volcano that is strongly correlated with variations in atmospheric temperature, leading us to conclude that meltwater from ice and snow strongly affects the seismic source mechanisms which is likely dominated by basal slip beneath the glaciers. The results presented here should inform future assessments of eruptive potential at Llaima volcano, as well as other ice-covered volcanoes in Chile and worldwide.

Keywords: Volcano-seismology, Cryoseismology, Llaima volcano, Volcano monitoring

\section{HIGHLIGHTS}

- We investigate micro-seismic activity at Llaima volcano in early 2019.

- We observe dozens of families of persistent repeating earthquakes.

- Estimated locations suggest sources at shallow depths near or beneath glaciers. 
- Long-term activity suggests strong relationship with snow and ice meltwater.

\section{INTRODUCTION}

Confident identification of recorded seismic signals and their source mechanisms is a fundamental aspect of assessing the eruptive potential of active volcanoes. Civil monitoring organizations and research groups must be prepared to recognize volcanic seismicity generated by fluid or magma ascent within volcanoes (Chouet and Matoza, 2013). However, seismic monitoring of active ice-covered volcanoes is complicated by glacial processes (e.g. basal slip, crevassing, ice fall) generating signals greatly resembling those produced by volcanism, raising the risk of misidentification (Weaver and Malone, 1976; Métaxian et al., 2003; Caplan-Auerbach and Huggel, 2007; Jónsdóttir et al., 2009; Thelen et al., 2013; Allstadt and Malone, 2014; Lamb et al., 2020). Therefore, detailed descriptions of glacial seismic sources at ice-covered active volcanoes is required before volcanic seismicity is used for assessing future eruption probability.

The Southern Chilean Volcanic Zone is home to $>19$ active ice-covered volcanoes that have erupted in recent history (Fig. 1b; Venzke, 2013). Llaima is one of the most active glacier-clad volcanoes in the region with up to 54 documented eruptions since the $17^{\text {th }}$ century (Naranjo and Moreno, 2005; Franco et al., 2019). The most recent activity in 2007-09 generated $7 \mathrm{~km}$ tall ash plumes and lahars from melting of glacial ice (Franco et al., 2019). As of 2016, $>14 \mathrm{~km}^{2}$ of ice was present on almost all sides of the volcano edifice (Fig. 1a; for a detailed description and discussion of how this glacial area was mapped, see Section 2 in Lamb et al., 2020). Most of these glaciers are thin (57 m maximum thickness in 2013; Gärtner-Roer et al., 2014) and retreating rapidly, with significant glacial area reductions in recent decades due to global climate change and eruptive activity (Reinthaler et al., 2019).

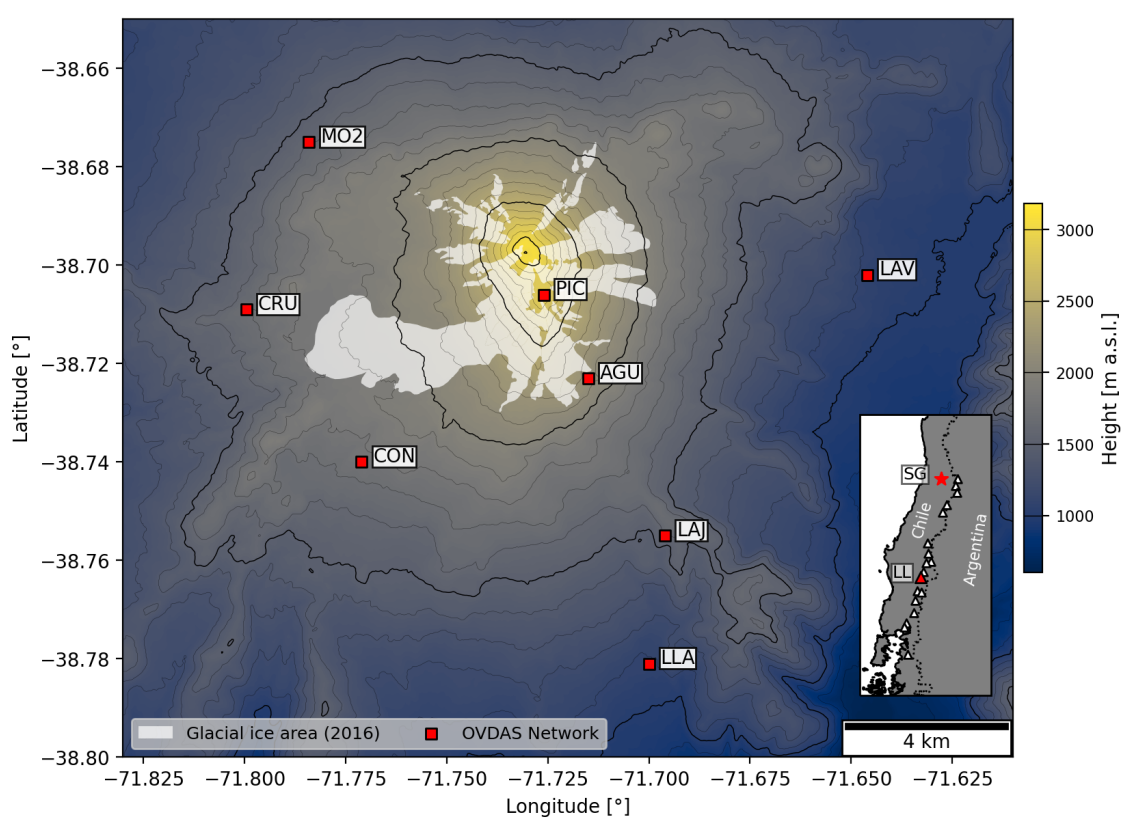

Figure 1. Map of Llaima volcano with the locations of OVDAS seismic stations (red squares) used in this study. Also marked are the mapped summit glacial areas marked as 'clear' or 'debris-covered' ice (white area). Thick and thin contours mark 500 and $100 \mathrm{~m}$ altitude intervals, respectively. Inset: Map of Southern Chile with the location of Llaima volcano (red triangle) and Santiago (red star, SG) marked. Also plotted are the locations of other ice-covered volcanoes within the Southern Volcanic Zone of Chile that have displayed eruptive activity in last 200 years (white triangles; Venzke, 2013). 
Llaima is continuously monitored by OVDAS (Observatorio Volcanológico de los Andes Sur ${ }^{1}$ ) who require timely and accurate identification of pre-eruptive seismic activity . The challenge in identifying volcanic activity at the volcano was highlighted by Lamb et al. (2020) that described multiple groups of low-frequency $(<5 \mathrm{~Hz})$ repeating earthquakes during a two month period in early 2015 . While a vast majority of these events were apparently too low-amplitude to be documented in the OVDAS seismic record, their low-frequency, repetitive nature resembles seismicity that can presage or accompany eruptive activity (e.g. Chouet et al., 1994; Iverson et al., 2006; Kendrick et al., 2014; Lamb et al., 2017). On the other hand, similar characteristics have been documented in seismic activity attributed to glacial processes such as crevassing (e.g. Mikesell et al., 2012), ice-fall (e.g. Jónsdóttir et al., 2009) and basal slip (e.g. Thelen et al., 2013; Allstadt and Malone, 2014). After characterizing the families of repeating events at Llaima, Lamb et al. (2020) concluded they likely originated from basal slip at the ice-rock interface beneath the glaciers on the edifice. Key evidence to support this conclusion include mixed arrival polarities at various seismic stations, as well as shallow locations near or beneath glaciers around the volcano summit.

While the evidence described by Lamb et al. (2020) highlighted the potential for persistent glacial seismic activity at Llaima volcano, the study could not provide concrete conclusions to it's own questions. In particular, the results could not completely rule out other possible sources of repeating seismicity at the volcano, including slow-slip rupture of volcanic materials (e.g. Bean et al., 2013), resonance of fluid-filled cracks (e.g. Chouet, 1996), and the interaction of snow and ice meltwater with magmatic hydrothermal fluids (e.g. Matoza et al., 2015; Park et al., 2019). Large error margins on locations for only a small number of repeating event families meant no strong conclusion could be made on the seismic source mechanism. Furthermore, the analysis of 2015 data raises the question of why was this persistent repeating seismic activity not previously documented? Llaima volcano has been instrumentally monitored by OVDAS since 1996 (Franco et al., 2019) and the glaciers on the edifice are supplemented by thick annual snowfall. Are the glaciers on the volcano changing (e.g. sliding faster) and the 2015 deployment was fortunate to be the first to record the repeating seismicity, or have these events been a long-term feature at the volcano but have been overlooked by previous studies?

In this study, we build on the findings of Lamb et al. (2020) by describing analysis of seismic data recorded in early 2019 over a similar two month period as in 2015. Here we aim to ascertain whether persistent, repetitive seismicity was recorded by the permanent OVDAS network during a two-month period in early 2019, using a similar but fine-tuned approach as the previous study. This includes using a different, amplitude-based location algorithm (instead of relative arrival times). We conclude by discussing the implications of our findings within the context of long-term seismic activity monitoring at Llaima, and how these events are likely related to variations in snow and ice meltwater.

\section{DATA AND METHODOLOGY}

\subsection{Data}

OVDAS are responsible for maintaining a network of seismometers around Llaima volcano, with 8 stations located within $10 \mathrm{~km}$ of the summit (Fig. 1a). This includes two short-period, vertical component sensors (PIC and LAJ) and six broadband, three-component seismometers (AGU, CON, CRU, LAV, LLA and MO2), all recording and telemetered to OVDAS at 100 samples per second. The network around Llaima also includes stations designed to help identify tectonic earthquakes (PA2, located $10.8 \mathrm{~km}$ SSE of LLA) or not available during the period of study (CNO, $2 \mathrm{~km} \mathrm{SSW}$ of LAV); neither of these stations were

1 part of Servicio Nacional de Geología y Minería (SERNAGEOMIN) 
used in this study. Additionally, weather data (temperature and precipitation) was monitored hourly at a station located in the town of Melipeuco ( $8 \mathrm{~km}$ south of LLA), maintained by the Agricultural Research Institute (INIA; data available via https://agrometeorologia.cl/, last accessed October 2021). For this study, we use the data recorded by all eight stations described above from 1 February until 1 April 2019.

Earthquakes recorded by the network around the volcano are manually picked and catalogued by OVDAS, with amplitudes and arrival times used to differentiate between volcanic and tectonic earthquakes. The majority of volcanic events are then divided into volcano-tectonic, long-period, or tremor events, and the temporal behaviour of each type has important implications for assessing the future eruptive potential of the volcano (see Chouet and Matoza, 2013, and references therein). Icequake events are also manually catalogued despite no mandate to do so, but until Lamb et al. (2020), little was known about their recurrence in the seismic record (Mora-Stock et al., 2014); potential low amplitude icequakes would frequently be recognised at stations located close to the glaciers (e.g. AGU, Fig. S1 in Supp. Materials) but usually not catalogued. To assist with our study of the seismic record in early 2019, we use the OVDAS seismic event catalogue from 1 February until 1 April 2019. The number of events catalogued by OVDAS during this period are described in the results section.

\subsection{Event detection}

To detect candidate seismic events at Llaima volcano in early 2019, we adopt a similar approach to that used in 2015 (Lamb et al., 2020). Trigger times were extracted from multiple stations using a short-term average/long-term average ratio (STA/LTA), on condition that an event was detected simultaneously at $\geq 3$ stations in the OVDAS network. Window lengths of 0.7 and $8 \mathrm{~s}$ were used for the short- and long-term windows, respectively, with a ratio of 3.5 used to define a detected event at each station. These parameters differ from those used in 2015 (minimum 2 stations, 1 and $9 \mathrm{~s}$ for short- and long-term windows, and a ratio of 5) but were decided using manual inspection of events detected over 24 hours of seismic data recorded at station AGU. Seismic data during this step were pre-filtered with a 1-10 Hz bandpass filter to improve the signal-to-noise ratio (SNR). Lastly, the catalogue of triggers was combined with the catalogue of events manually compiled by OVDAS over the same time period, with duplicates removed. This last step differs from the 2015 study (Lamb et al., 2020) which only used the OVDAS catalogue for comparison purposes.

\subsection{Identifying repeating events}

The next step is to find repetitive seismic events (i.e. families) within the catalog of candidate seismic events compiled by the multi-station STA/LTA algorithm. This step follows a similar unsupervised clustering methodology to that used in Lamb et al. (2020) for the 2015 families, which is itself based on the approach used to recognise repeating events at Mt Rainier volcano (Carmichael, 2013; Allstadt and Malone, 2014). Each event is cross-correlated with all other events within each day, using a minimum cross-correlation coefficient of 0.8 to define 2 events as closely matching; this is higher than the 0.7 used for repeating events in 2015. The first $5 \mathrm{~s}$ of each event waveform is used, which is sufficient to maximise the SNR of each event. As station AGU had the highest number of detected events, waveforms from this station were used to build the catalog of families. Families of repeating waveforms were defined using a hierarchical clustering method similar to that used by Buurman and West (2013) and Lamb et al. (2017); the scipy . cluster. hierarchy Python package is used for this step (For more details, see https://docs.scipy.org/doc/scipy/reference/, last accessed October 2021). Next, for each day a median waveform stack is computed for each family of 2 or more events, which are then compared with all other stacks across the whole time period to find larger, multi-day families. The last step ensures a more complete repeating event catalogue by using a frequency-domain approach with a overlap-add method, vectorization, 
and fast normalization to increase computation efficiency (SEC-C; Senobari et al., 2019). This step scans the entire time period with stacked waveforms from all multi-day and non-matched families (i.e. not multi-day) to find any events potentially overlooked in previous steps. This last step differs from Lamb et al. (2020) which only used multi-day families to scan for missed events, potentially underestimating the total number of families taking place in 2015.

\subsection{Event locations}

Arrival time location methods cannot be used on each individual event in each family as most are emergent and/or have onsets obscured by background noise. Since these events are repetitive, one option is to remove background noise be generating mean waveforms (i.e. stacks) of the respective families at each station. This approach was effective in locating families of icequakes at Mt Rainier volcano (Allstadt and Malone, 2014), but was less effective for similar events at Llaima in 2015 (Lamb et al., 2020). Large errors $(\sim 500 \mathrm{~m})$ can be introduced by small offsets in stacking, which is difficult if the original events have low SNRs, or if the shallow velocity model for the area is not known. Here we adopt an approach which uses the full waveform instead of relying on relatively accurate arrival time measurements, and was originally developed for locating episodic tremor and slip in the northern Cascadian subduction zone (Wech and Creager, 2008). Locations are estimated with a cross-correlation method that maximizes signal coherency among seismic stations within the network.

Centroid locations are estimated by cross-correlating all station pairs and performing a 3D grid search over potential source-location S-wave lag times that optimize the cross-correlations. The objective function $M\left(x^{\text {grid }}\right)$ is a weighted L1 norm on all pairs of cross-correlograms (Wech and Creager, 2008):

$$
M\left(x^{\text {grid }}\right)=\sum_{i=1}^{N} \sum_{j=i+1}^{N} \frac{C_{i j}^{\text {max }}-C_{i j}\left(\delta t_{i j}\left(x^{\text {grid }}\right)\right)}{\Delta C\left(C_{i j}^{\text {max }}\right)}
$$

where $x^{\text {grid }}$ is a target source position, $C^{i j}$ is the normalized cross correlogram between the $i$ th and $j$ th functions, $N$ is the number of seismograms, $C_{i j}^{\max }$ is the maximum value of the cross-correlogram, and $\delta t_{i j}\left(x^{\text {grid }}\right)=t_{i}\left(x^{\text {grid }}\right)-t_{j}\left(x^{\text {grid }}\right)$ is the predicted differential S-wave travel time between the $i$ th and $j$ th station using $v_{s}=2.5 \mathrm{~km} . \mathrm{s}^{-1}$ (Franco et al., 2019). Thus, for each possible grid location, we predict the lag time, $\delta t_{i j}\left(x^{\text {grid }}\right)$, between station pairs and evaluate its corresponding correlation value from the cross-correlogram $C_{i j}\left(\delta t_{i j}\left(x^{\text {grid }}\right)\right)$. Traditional location methods seek solutions that minimizes the time difference between predicted travel time and peak lag time, but this method instead minimizes the distance between the peak correlation, $C_{i j}^{\max }$, and the predicted correlation, $C_{i j}\left(\delta t_{i j}\left(x^{g r i d}\right)\right)$. Using only those observations with $C_{i j}^{\max }>0.5$, we maximize network coherency with respect to variations in $x_{\text {grid }}$ by minimizing the sum over station pairs of this vertical correlation distance, $C_{i j}^{\text {max }}-C_{i j}\left(\delta t_{i j}\left(x^{\text {grid }}\right)\right)$ inversely weighted by the uncertainty $\Delta C\left(C_{i j}^{\max }\right)$.

The above calculation was performed within the 'enveloc' Python package (Wech and Creager, 2008). This optimization problem was performed on a grid with $0.005^{\circ}$ lateral and $100 \mathrm{~m}$ depth intervals (down to $5 \mathrm{~km}$ ) centered on the summit of the volcano. However, the 'enveloc' package was originally developed for searching for locations across a much larger area than that which is used here so topography was previously not taken into account, and stations were located at the top of the grid (i.e. the surface). With a vertical difference of $\sim 1800 \mathrm{~m}$ between stations $7 \mathrm{~km}$ apart (PIC and LLA), we customized the grid location search to account for the sharp topography around Llaima volcano. The top of the grid is set as the summit of the volcano, and each station was then embedded within the grid at the relevant coordinates and depth. Each 
grid point was then compared to a topographic map, all points above the topography were excluded and the remaining grid point with the lowest misfit, defined as $C_{i j}^{m a x}-C_{i j}\left(x^{b e s t}\right)$, was picked as the source location. Centroid location results at or too close to the edge of the search grid were rejected.

\subsection{Qualitative event magnitude estimation}

For each family successfully located on Llaima volcano we can also estimate their individual event magnitudes, assuming that each family is derived from a fixed location. Event magnitudes, together with characteristic frequencies, of glacially derived seismicity may also provide evidence towards the source mechanism of each family (Podolskiy and Walter, 2016). Magnitudes for long-period and tremor events detected at Llaima by OVDAS are not routinely calculated, therefore we adopt an approach previously used for qualitatively estimating magnitudes of micro-seismic events detected at Hekla volcano, Iceland (Eibl et al., 2014). This approach uses recorded amplitudes of located regional seismic events to estimate the magnitudes of local events using their source amplitudes. The 37 regional events used here were recorded and documented by Centro Sismológico Nacional (CSN) and OVDAS, occurring up to $250 \mathrm{~km}$ from Llaima volcano, up to depths of $113 \mathrm{~km}$, at azimuths between 170 and $30^{\circ}$, and with calculated local magnitudes of $0.5-4.0$ (Table S2 and S3 in Supp. Material).

Before estimating magnitudes, site effects must be removed from the recorded seismic data at each station. Coda waves can be used to estimate site amplification (Aki and Ferrazzini, 2000; Battaglia and Aki, 2003; Kumagai et al., 2010; Eibl et al., 2014). For each regional event recorded by CSN we used a 30 $\mathrm{s}$ time window that begins at a time that was twice the arrival time of the estimated arrival of the S-phase. Each waveform was instrument corrected and bandpass filtered to $1-10 \mathrm{~Hz}$ before root mean square values in $5 \mathrm{~s}$, non-overlapping windows were calculated (Aki, 1969). All RMS values were averaged and compared to the chosen reference station, MO2. This station was selected as the reference station as it had the least interrupted seismic dataset and least local high frequency background noise. The resulting correction factors are provided in Table S1 in Supplementary Materials.

To estimate source amplitudes for each of the regional events, we first remove the site amplification and instrument response, before filtering to $1-10 \mathrm{~Hz}$. The maximum of the smoothed Hilbert Transform was used as maximum amplitude $A_{i}$ at each station $i$. The amplitude at the source, $A_{0}$, was then calculated at each station based on (Battaglia and Aki, 2003)

$$
A_{0_{i}}=\frac{A_{i} r_{i}}{e^{B r_{i}}}
$$

with

$$
B=\frac{\pi f}{Q \beta}
$$

where $r$ is the source-to-receiver distance, $f$ is the central frequency, $\beta$ is wave velocity $\left(2.5 \mathrm{~km} . \mathrm{s}^{-1}\right)$, and $Q$ is the quality factor for attenuation (100). A linear regression was then implemented with the logarithm of the mean source amplitudes versus the published local magnitudes. Finally, to estimate the local magnitudes of the events detected in this study at Llaima, we first calculate their source amplitudes using estimated source location of each family of repeating events, under the assumption that families of repeating events are derived from a relatively fixed source location. These source amplitudes were then converted to a local magnitude using the regression line calculated using regional events. 


\section{RESULTS}

\subsection{Seismic activity}

Between 1 February and 1 April 2019, we detected 6,647 events at Llaima volcano (Fig. 2a). Higher numbers of events were detected at stations closer to the summit, and hourly rates of detections appear to show a diurnal variation that is inversely correlated with background seismic noise levels (Fig. S3). During the same time period, OVDAS manually catalogued a total of 967 events, including 666 long-period, 1 volcano-tectonic, 271 rockfall, and 29 icequakes (Fig. 2c, S2). Using the catalogue of automatic detections, we identified 2,006 repeating events across 82 families (Fig. 2b, 3). Of these, 370 events were already featured in the OVDAS catalogue, including 270 classified as long-period events. The largest of these families contained 207 events (Family 5; Fig. 3). The daily rate of seismicity, including repeating events, show no obvious indications of cyclic activity or significant changes in rates except for $18 \mathrm{March}$. On that date, a peak in seismic activity (not seen in repeating events; Fig. 2b) occurs shortly after a brief period of rainfall recorded at the town of Melipeuco, approximately $17 \mathrm{~km} \mathrm{SSE}$ of the volcano summit (Fig. 2d).

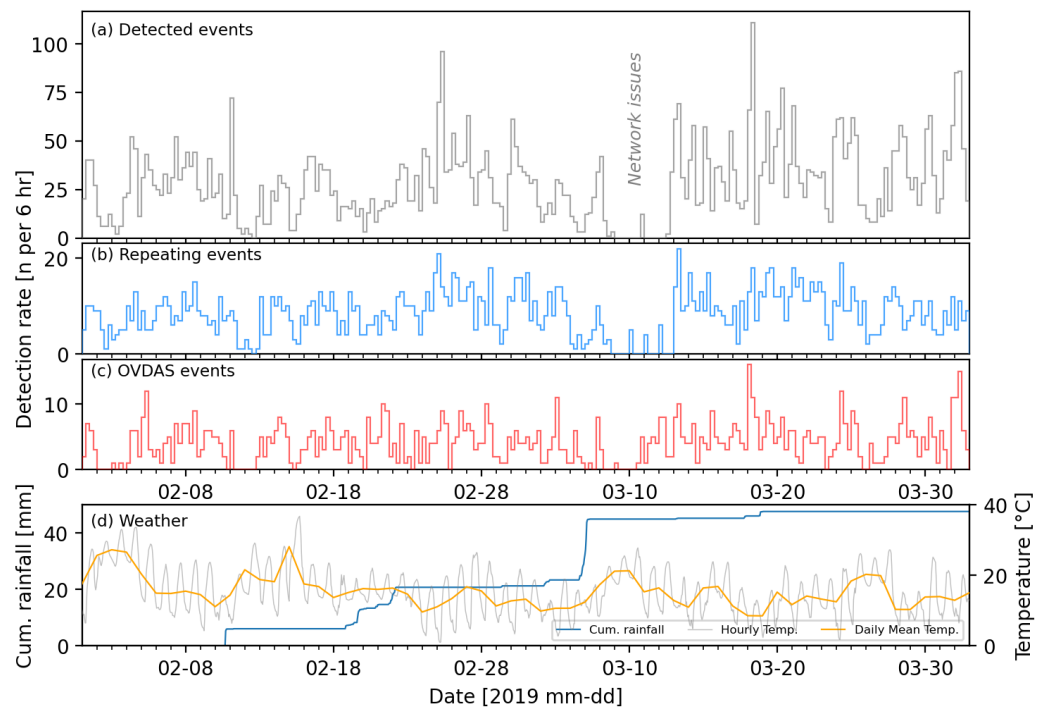

Figure 2. Rates for (a) events automatically detected, (b) events classified as repeaters, and (c) seismic events manually classified by OVDAS from 1 February to 1 April 2019 in 3-hour bins. (d) Cumulative rainfall (blue line) and variations in temperature on an hourly (grey) and daily rate (orange line) at the weather station located in Melipeuco.

\subsection{Locations}

Locations were estimated for all families containing at least 30 events $(n=17$, highlighted with blue diamonds in Fig. 3). Due to low SNRs for individual events, locations could only be reliably estimated using mean waveforms for each family at each station, generated by stacking waveforms of all events. An example of an estimated location is given in Figure 4 for family 4; see Figs. S5 - S21 for all other locations. Out of the 17 families for which locations were estimated, 5 were rejected due to locations at or too close to the edge of the search grid (Families 10, 19, 36, 71, and 73; Figs. S11, S13, S17, S20, S21). The remaining 12 families are all located at shallow depths $(<500 \mathrm{~m})$ around the summit of the volcano (Fig. 5). Note that 5 of these families are located at or within close approximation to each other (Families 2 and 64, and 


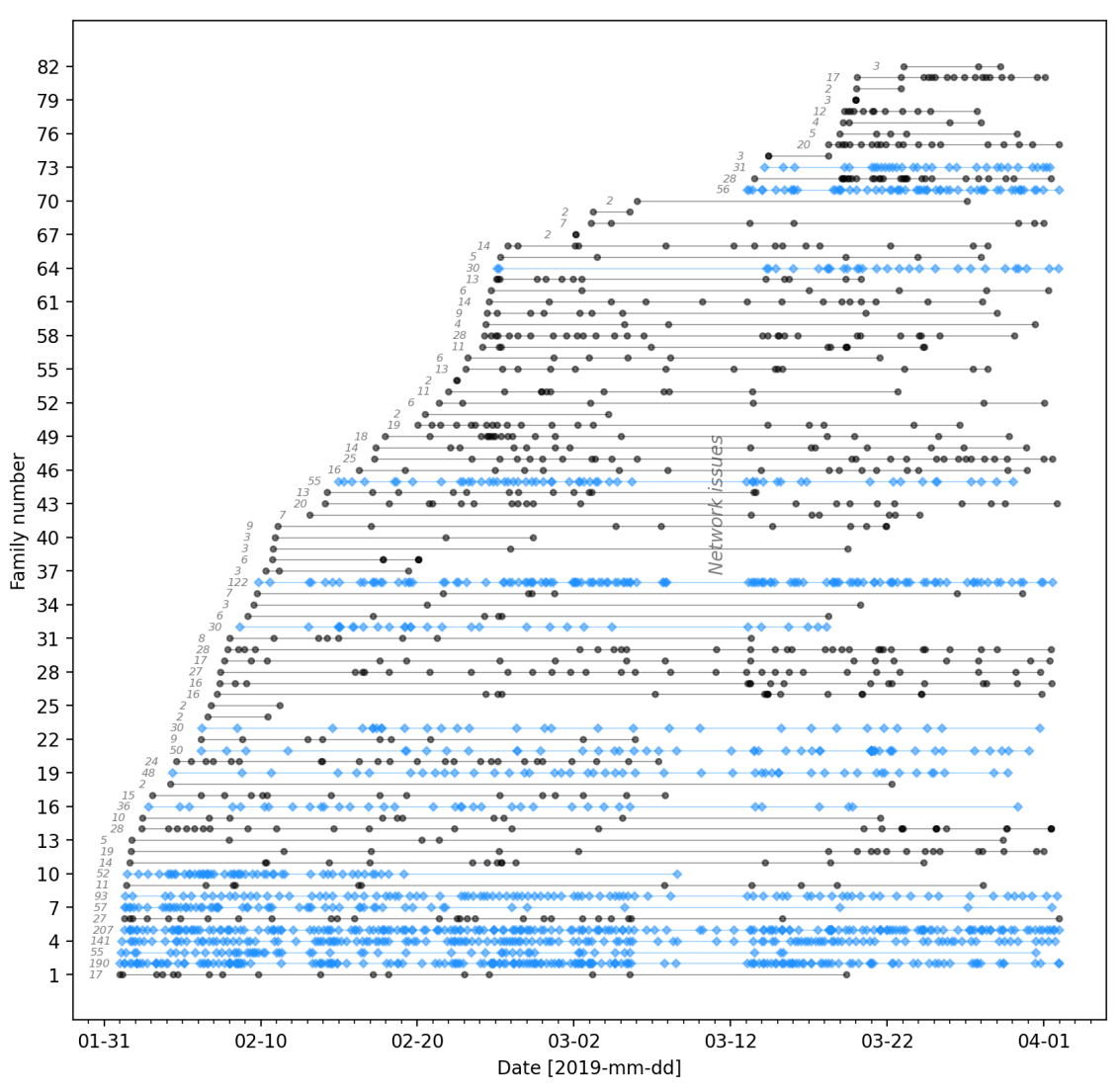

Figure 3. Catalog of family occurrence in our dataset. Each plotted point represents the time of an event, and lines join events from the same family. The total number of events in each family is noted before the first event. Families containing 30 or more events are highlighted using blue diamonds for the individual events.

Families 16, 21, and 32). With the exception of family 7, all located families were located directly beneath or at the edge of mapped glacial areas around the summit of the volcano.

\subsection{Qualitative magnitude estimates}

Local magnitudes were estimated for each event within all families for which locations could be calculated (Fig. 5). Local magnitudes for all located repeating events fell within the $0.9-1.5$ range, with little distinct difference between families (Fig. 6). As we assumed straight wave propagation between source and receiver, we underestimate $A_{0}$ for regional events which, in turn, implies that local magnitudes for all repeating events are overestimated; therefore, the values calculated here represent a maximum feasible value.

\section{DISCUSSION}

Here we have presented results from detailed analysis of seismic data collected at Llaima volcano in early 2019 , with the aim of building on previous work (Lamb et al., 2020) to understand the prevalence of icequakes from glaciers around the summit. The key differences from Lamb et al. (2020) is this study uses seismic data from the permanent OVDAS monitoring network around the volcano (Fig. 1), a new approach for calculating event locations that does not rely on accurate arrival time picks, as well as a first attempt at quantifying local magnitudes of the repeating seismic events. 


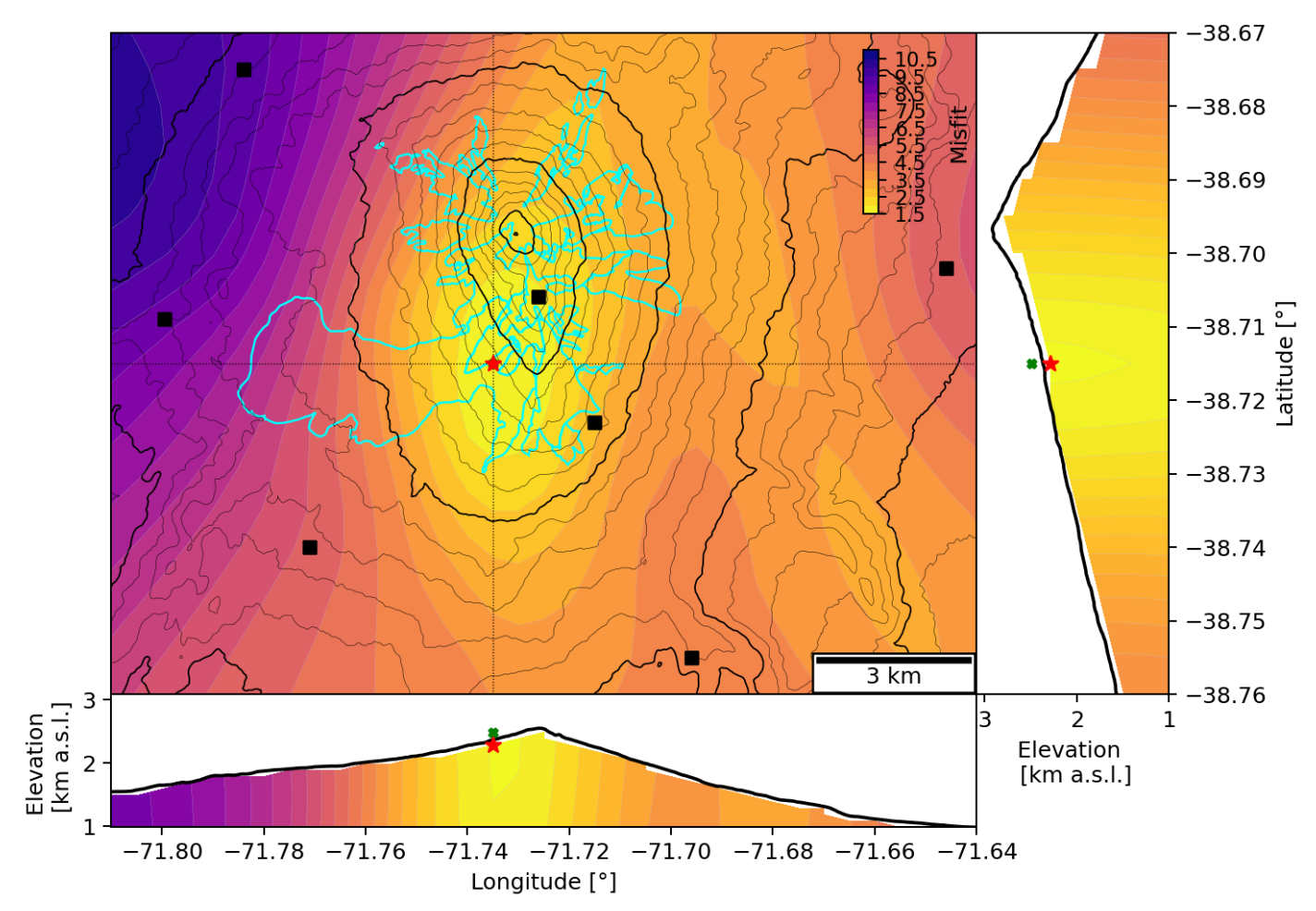

Figure 4. Example output of location method used, here illustrating the location of Family 4 (red star). The green square in each cross section panel (right and bottom) shows the location if topography was not accounted for. Dotted lines indicate the profiles of the cross-section panels (right and bottom), centred on the final location of the family. Blue lines on main panel outline the mapped summit glacial areas. Black squares are locations of OVDAS seismic stations.

The persistent repeating seismicity observed in 2015 (Lamb et al., 2020) appears to be continuing in 2019, albeit with higher numbers of detected events (Fig. 2a, b). The elevated levels of activity in 2019 relative to 2015 is reflected by the higher number of manually catalogued events by OVDAS (Fig. 2c), with 967 events in 2019 compared to 490 in 2015. Furthermore, the seismic activity in 2019 appears to show no relation to changes in weather (Fig. 2d) which was also observed in 2015 (Lamb et al., 2020). One key difference between 2019 and 2015 is that the number of families of repeating events is much greater in the former than the latter time period, with 82 and 11, respectively. This is likely due to a slightly different criteria for classifying families in each analysis, in particular, with the 2015 study only using stacks from multi-day families to scan for missed events with the SEC-C algorithm (Senobari et al., 2019). If we use the same criteria in 2019 as that used in 2015, we find only 12 families in total (not shown here).

Compared to 2015, the new approach for calculating locations of repeating events is more successful in 2019 (Fig. 5). The results suggest that the locations of all the largest detected families are shallow $(<100$ $\mathrm{m}$ ) and almost all beneath or near the edge of glaciers around the summit of Llaima volcano, with the sole exception being family 7 (Fig. S9). These location estimates represent an improvement on those in 2015, with a greater number of families located and more robust estimation of location errors. However, there remain significant errors (represented here by the misfit) in locations, particularly in the vertical component (e.g. see cross-section panels in Fig. 4). This is due to the use of a 1D velocity model for Llaima volcano, as no shallow 2D velocity model is currently available for the volcano. Nevertheless, the estimated locations and depths for most families support the hypothesis that these were generated by glacial activity rather than volcanic. 


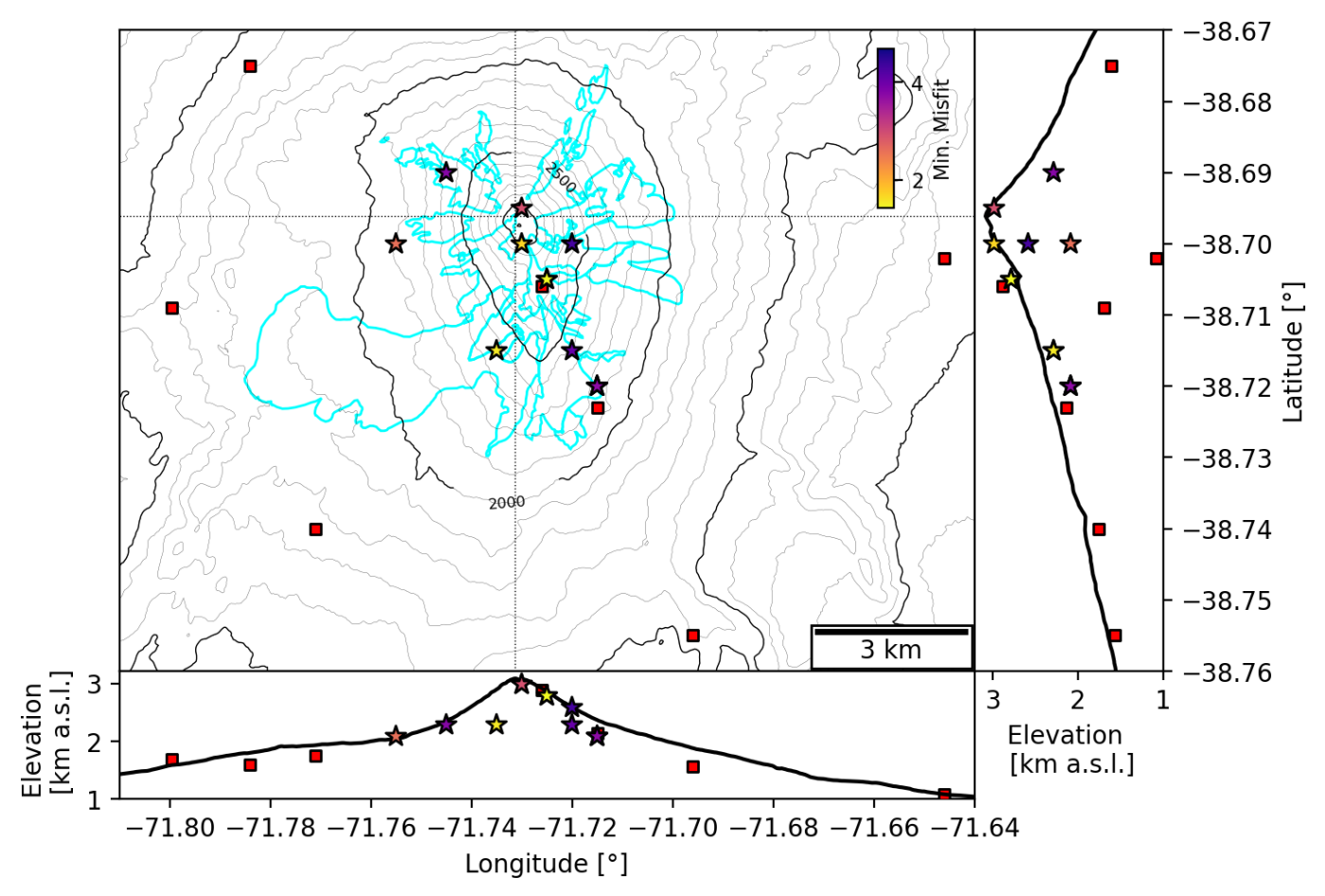

Figure 5. Results for all families that were located (stars). Each star is coloured by the minimum misfit for their location. Dotted lines indicate the profiles of the cross-section panels (right and bottom). Red squares indicate the location of OVDAS seismic stations, and blue lines outline the mapped summit glacial areas.
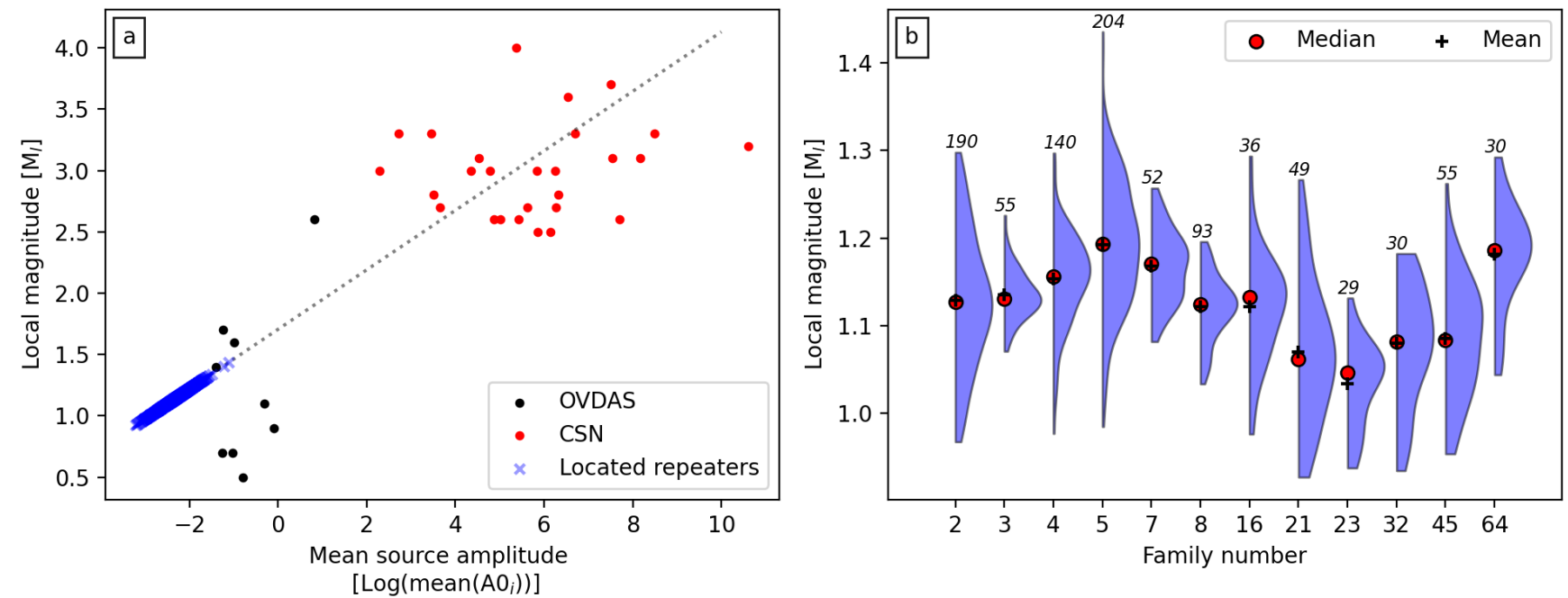

Figure 6. Results of qualitative local magnitude estimates. (a) Local magnitudes of located repeating events in this study (blue cross) estimated using the linear regression (dotted line) calculated from regional events detected by CSN (red dots) and OVDAS (black dots). (b) Half-violin plots for each located family showing their distribution of estimated local magnitudes with rotated kernel density plots (blue). Also plotted is the median (red circle) and mean (black cross) of the local magnitude for each family. Numbers above each half-violin plot indicate the total number of events within each family.

Qualitative event magnitudes for each located family suggest little distinct differences in energies between families (Fig. 6). The lack of obvious differences between each family suggests they may be generated by 
a similar source mechanism, but at different locations. A review of glacial seismicity has suggested that source mechanisms may be identified via their frequency versus magnitude relationship (see Fig. 14 in Podolskiy and Walter, 2016). For the repeating events for which we have estimated their local magnitudes, their central frequencies lie in the range of 3.5 to $6.5 \mathrm{~Hz}$ which would be associated with stick-slip activity at the base of glaciers. The relatively thin ice thicknesses on Llaima volcano (maximum $57 \mathrm{~m}$ in 2013; Gärtner-Roer et al., 2014) may preclude the occurrence of stick-slip activity due to insufficient normal stresses. However, we argue that the steepness of volcano edifice provides conditions to induce stick-slip activity at the base of the glaciers, as indicated by the locations of families on the steepest parts of the edifice (see cross-section panels in Fig. 5).

The estimation of locations (and in turn, the event magnitudes) using waveform stacks assumes that the source for each event within each family remains fixed. Geller and Mueller (1980) suggest highly correlated waveforms such as those found in repeating event families must be within a quarter wavelength so as to not be influenced by the structure between two source locations. Central frequencies for events within the largest families range from 3.5 to $6.5 \mathrm{~Hz}$ which, together with $v_{s}=2.5 \mathrm{~km} . \mathrm{s}^{-1}$, suggest the spread of locations should be no more than approximately 96 to $179 \mathrm{~m}$. However, cross-correlations between all events relative to the first detected event highlight a gradual de-correlation over the lifespan of each family (Fig. S4; note these are not the same cross-correlation values used to assign events into families). A similar observation was made for icequake families at Mt Rainier volcano (Thelen et al., 2013) and is likely the result of either changes in source mechanism, modifications to the source-receiver pathway, or the slow migration of the source over time. Here we favour the latter option, considering the other options would likely give abrupt changes in correlation over time, not somewhat continuous. For example, significant precipitation events at Mt Rainier produced abrupt but short-lived reductions in cross-correlation values (See Fig. 5 in Thelen et al., 2013).

Before conclusions can be drawn from short-term observations and analysis, the results from this study as well as Lamb et al. (2020) must be placed in the context of the long-term seismic activity of Llaima volcano (Fig. 7). From 1 January 2013 to 31 December 2020, a total of 11,079 LP earthquakes were cataloged at Llaima volcano and daily event rates over that time show a clear annual fluctuation with higher event rates in the austral summer (December to April) versus the winter (May to November; Fig. 7a, c). Over the same time period, volcanic activity at Llaima was minimal aside from a brief but intense swarm of volcanic LP events from 1-3 October 2017, peaking with 460 events on 2 October (Fig. 7a). When compared with weather measurements from a station located in Melipeuco (Fig. 7b), the seismic event rates show a strong correlation with median daily temperatures and an inverse correlation with median daily precipitation rates (Fig. 7c). There is also a strong diurnal cycle in event rates from 2013 to 2020 with lower detection rates from 1000 to 1800 local time (Fig. 7d). Evidence from our 2019 analysis suggests this is likely due to increased seismic noise from wind and human sources drowning out smaller magnitude events (Fig. S3). A similar observation was made during the analysis of seismic events related to the glaciers on Cotopaxi volcano (Métaxian et al., 2003).

Annual cycles in seismic activity correlating with variations in precipitation or temperature have been observed at other ice- and snow-covered volcanoes (Jónsdóttir et al., 2009; Allstadt and Malone, 2014; Park et al., 2019; Castaño et al., 2020). Low frequency earthquakes at volcanoes can be triggered by rainfall (e.g. Matthews et al., 2009) or snowfall (Allstadt and Malone, 2014) however LP activity at Llaima is inversely correlated with precipitation and positively correlated with temperatures (Fig. 7c). Therefore, we interpret the annual cycle in activity at Llaima as the result of yearly melting of snow and ice around the summit of the volcano. An increase in meltwater at the surface can increase the frequency of basal slip beneath 

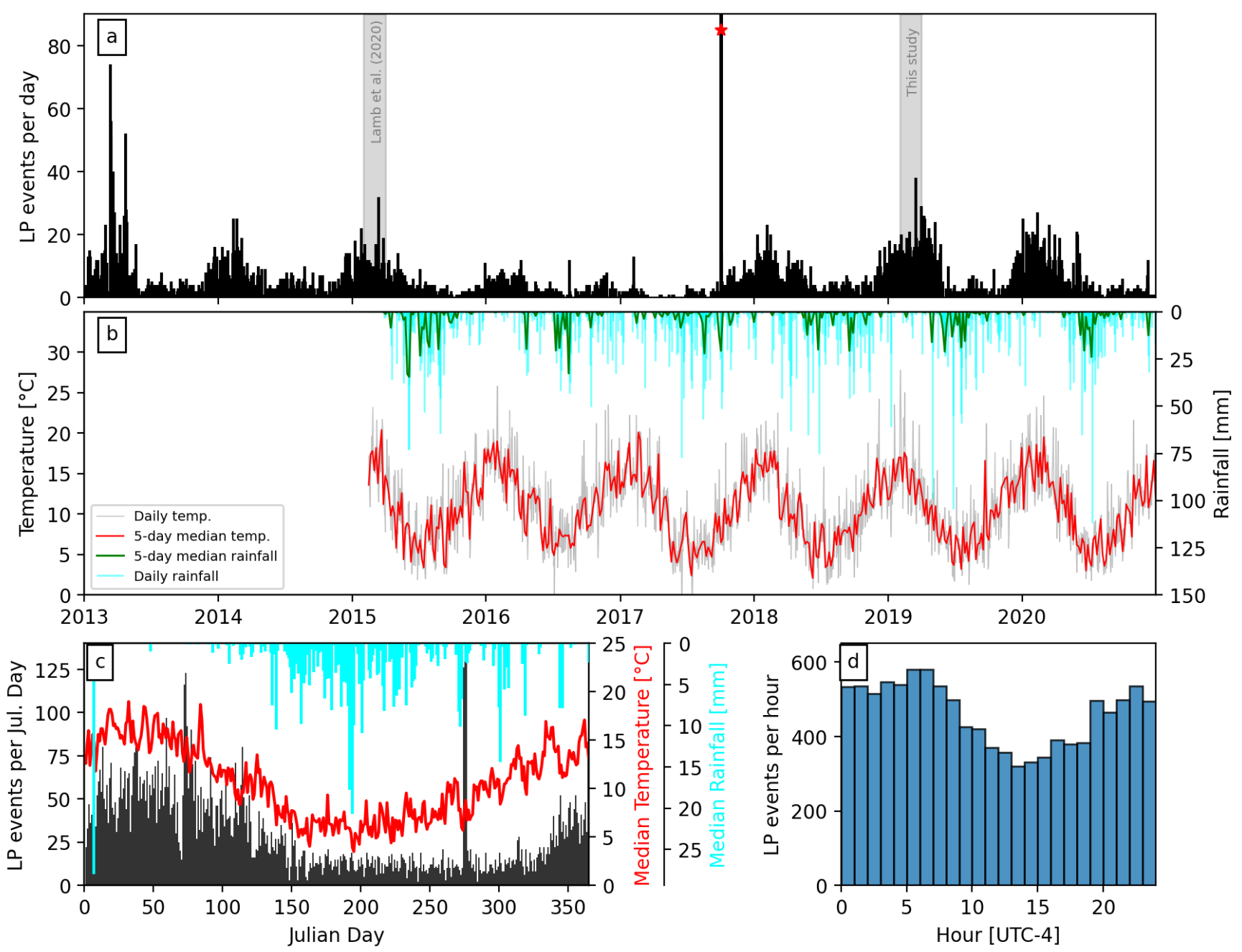

Figure 7. Long-term seismic activity and weather at Llaima volcano. (a) Number of LP seismic events manually catalogued per day by OVDAS at Llaima volcano from 1 January 2013 to 31 December 2020. Grey areas mark time periods studied in Lamb et al. (2020) and this study. Red star marks time period of intense volcanic LP activity observed at Llaima volcano. (b) Daily and 5-day median temperature (grey and red lines) and precipitation (cyan bars and green line) measurements from weather station located in Melipeuco, $8 \mathrm{~km}$ south of station LLA. Weather data is not available prior to 15 February 2015. (c) Histogram of LP event rates binned by the Julian day of their detection for all events from 2013 to 2020 (black bars). [Note that the high values at Julian day 275 is due to the volcanic LP swarm detected in October 2017.] Also plotted is the median temperature (red line) and median precipitation rates (cyan bars) for each julian day from 2015 to 2020. (d) Histogram of LP event rates by hour from 2013 to 2020.

glaciers at the ice-rock interface. Fluctuations in meltwater flow can directly modulate the frequency of basal slip beneath glaciers due to changes in shear strength with effective pressure (e.g. Mikesell et al., 2012; Roeoesli et al., 2016; Nanni et al., 2020). Percolation of meltwater into the shallow subsurface of Llaima volcano may also increase the frequency of slow-slip failure of critically stressed fractures within poorly consolidated volcanic material (e.g. Bean et al., 2013; Heap et al., 2015). However, experimental observations suggest such a mechanism is unlikely (but not impossible) to generate repetitive seismicity like those observed in 2015 and 2019 at Llaima (Heap et al., 2015). The ingress of meltwater into the edifice may also lead to the excitation of repetitive low magnitude LP events caused by sudden pressure changes within a shallow hydrothermal system. A similar mechanism was suggested for low-frequency seismic activity at Nevado del Ruiz and Mount St Helens volcanoes (Leet, 1988; Matoza et al., 2015) as well as for 
causing annual seismic cycles at Ngauruhoe volcano (New Zealand; Park et al., 2019). Petrological analysis of eruptive products from Llaima volcano has suggested that magma is stored at very shallow depths $(\leq 4$ $\mathrm{km}$ ) as a series of dyke intrusions beneath the summit vent where they undergo intense degassing between eruptions (de Maisonneuve et al., 2012; Ruth et al., 2016, 2018). Therefore, it is possible that a shallow hydrothermal system is present within Llaima volcano and is interacting on an annual basis with snow and ice meltwater.

Identifying specific source mechanisms for each of the repeating families described in this study is difficult due to the low signal-to-noise ratios of the seismic signals. However, evidence from locations, local magnitudes, and drifting source locations suggest that the majority of background long-period seismic activity is generated by basal slip beneath the glaciers. Nevertheless, due to the large number of identified families (Fig. 3) it may be reasonable to conclude that all three of the mechanisms affected by meltwater may be occurring at Llaima volcano.

\section{CONCLUSIONS}

Rigorous interpretation of the source mechanisms of low-frequency earthquakes is vital for assessing the future eruptive potential of ice-covered volcanoes, particularly as icequakes can share many characteristics with volcanic long-period events. Here we present a detailed analysis of two months of seismic data recorded at Llaima volcano, Chile, in 2019. Over 2,000 repeating low frequency earthquakes were identified across 82 different families, the largest of which contained over 200 events and was persistent for the whole time period of analysis. Locations of the largest families indicate shallow sources near or directly beneath glaciers present around the summit of the volcano. Long-term seismic activity reveals that these repeating seismic events are part of an annual seismic cycle that is strongly correlated with atmospheric temperature. Therefore, we conclude that the low-frequency repeating events seen at Llaima volcano are triggered by variations in meltwater affecting basal slip beneath the glaciers, as well as interactions with critically stressed fractures and a shallow hydrothermal system within the edifice. The information presented here should inform future making during seismic crises at Llaima volcano as well as other ice-covered volcanoes in Chile and globally.

\section{ACKNOWLEDGMENTS}

This research was performed while ODL held an NRC Research Associateship with the U.S. Army Research Laboratory/Army Research Office while based at the University of North Carolina at Chapel Hill. The authors wish to thank all analysts at OVDAS who were involved in performing routine manual cataloging of seismic activity at Llaima volcano and whose work was valuable for this analysis.

\section{DECLARATION OF INTERESTS STATEMENT}

The authors declare that they have no known competing financial interests or personal relationships that could have appeared to influence the work reported in this paper.

\section{REFERENCES}

Aki, K., 1969. Analysis of the seismic coda of local earthquakes as scattered waves. Journal of Geophysical Research 74,615-631. doi:10.1029/JB074i002p00615. 
Aki, K., Ferrazzini, V., 2000. Seismic monitoring and modeling of an active volcano for prediction. Journal of Geophysical Research: Solid Earth 105, 16617-16640. doi:10 . 1029 / 2000 JB900033.

Allstadt, K.E., Malone, S.D., 2014. Swarms of repeating stick-slip icequakes triggered by snow loading at Mount Rainier volcano. Journal of Geophysical Research: Earth Surface 119, 1180-1203. doi:10 . $1002 / 2014 \mathrm{JF} 003086$.

Battaglia, J., Aki, K., 2003. Location of seismic events and eruptive fissures on the Piton de la Fournaise volcano using seismic amplitudes. Journal of Geophysical Research 108, 2364. doi:10.1029/ 2002 JB002193.

Bean, C.J., De Barros, L., Lokmer, I., Métaxian, J.P., O’ Brien, G., Murphy, S., 2013. Long-period seismicity in the shallow volcanic edifice formed from slow-rupture earthquakes. Nature Geoscience 7 , 71-75. doi:10.1038/ngeo2027.

Buurman, H., West, M.E., 2013. Magma fracture and hybrid earthquakes in the conduit of Augustine Volcano. Geophysical Research Letters 40, 6038-6042. doi:10 .1002/2013GL057864.

Caplan-Auerbach, J., Huggel, C., 2007. Precursory seismicity associated with frequent, large ice avalanches on Iliamna volcano, Alaska, USA. Journal of Glaciology 53, 128-140. doi:10.3189/ 172756507781833866.

Carmichael, J.D., 2013. Melt-triggered seismic response in hydraulically-active polar ice: Observations and methods. Ph.D. thesis. University of Washington.

Castaño, L.M., Ospina, C.A., Cadena, O.E., Galvis-Arenas, B., Londono, J.M., Laverde, C.A., Kaneko, T., Ichihara, M., 2020. Continuous monitoring of the 2015-2018 Nevado del Ruiz activity, Colombia, using satellite infrared images and local infrasound records. Earth, Planets and Space 72,81. doi:10.1186/ s40623-020-01197-z.

Chouet, B.A., 1996. Long-period volcano seismicity: its source and use in eruption forecasting. Nature 380, 309-316. doi:10.1038/380309a0.

Chouet, B.A., Matoza, R.S., 2013. A multi-decadal view of seismic methods for detecting precursors of magma movement and eruption. Journal of Volcanology and Geothermal Research 252, 108-175. doi:10.1016/j.jvolgeores.2012.11.013.

Chouet, B.A., Page, R.A., Stephens, C.D., Lahr, J.C., Power, J.A., 1994. Precursory swarms of long-period events at Redoubt Volcano (1989-1990), Alaska: Their origin and use as a forecasting tool. Journal of Volcanology and Geothermal Research 62, 95-135.

Eibl, E.P., Bean, C.J., Vogfjörd, K., Braiden, A., 2014. Persistent shallow background microseismicity on Hekla volcano, Iceland: A potential monitoring tool. Journal of Volcanology and Geothermal Research 289, 224-237. doi:10.1016/j.jvolgeores.2014.11.004.

Franco, L., Palma, J.L., Lara, L.E., Gil-Cruz, F., Cardona, C., Basualto, D., San Martín, J., 2019. Eruptive sequence and seismic activity of Llaima volcano (Chile) during the 2007-2009 eruptive period: Inferences of the magmatic feeding system. Journal of Volcanology and Geothermal Research 379, 90-105. doi:10.1016/j.jvolgeores.2019.04.014.

Geller, R.J., Mueller, C.S., 1980. Four similar earthquakes in central California. Geophysical Research Letters 7, 821-824. doi:10.1029/GL007i010p00821.

Gärtner-Roer, I., Naegeli, K., Huss, M., Knecht, T., Machguth, H., Zemp, M., 2014. A database of worldwide glacier thickness observations. Global and Planetary Change 122, 330-344. doi:10.1016/ j.gloplacha.2014.09.003.

Heap, M.J., Kennedy, B.M., Pernin, N., Jacquemard, L., Baud, P., Farquharson, J.I., Scheu, B., Lavallée, Y., Gilg, H.A., Letham-Brake, M., et al., 2015. Mechanical behaviour and failure modes in the Whakaari 
(White Island volcano) hydrothermal system, New Zealand. Journal of Volcanology and Geothermal Research 295, 26-42. doi:10.1016/j.jvolgeores.2015.02.012.

Iverson, R.M., Dzurisin, D., Gardner, C.A., Gerlach, T.M., LaHusen, R.G., Lisowski, M., Major, J.J., Malone, S.D., Messerich, J.A., Moran, S.C., Pallister, J.S., Qamar, A.I., Schilling, S.P., Vallance, J.W., 2006. Dynamics of seismogenic volcanic extrusion at Mount St Helens in 2004-05. Nature 444, 439-43. doi:10.1038/nature05322.

Jónsdóttir, K., Roberts, R., Pohjola, V., Lund, B., Shomali, Z.H., Tryggvason, A., Böðvarsson, R., Bövarsson, R., 2009. Glacial long period seismic events at Katla volcano, Iceland. Geophysical Research Letters 36, L11402. doi:10.1029/2009GL038234.

Kendrick, J.E., Lavallée, Y., Hirose, T., Di Toro, G., Hornby, A.J., De Angelis, S., Dingwell, D.B., 2014. Volcanic drumbeat seismicity caused by stick-slip motion and magmatic frictional melting. Nature Geoscience 7, 438-442. doi:10 .1038/NGEO2146.

Kumagai, H., Nakano, M., Maeda, T., Yepes, H., Palacios, P., Ruiz, M., Arrais, S., Vaca, M., Molina, I., Yamashima, T., 2010. Broadband seismic monitoring of active volcanoes using deterministic and stochastic approaches. Journal of Geophysical Research 115, B08303. doi:10.1029/ 2009 JB006889.

Lamb, O.D., De Angelis, S., Wall, R.J., Lamur, A., Varley, N.R., Reyes-Dávila, G.A., Arámbula-Mendoza, R., Hornby, A.J., Kendrick, J.E., Lavallée, Y., 2017. Seismic and experimental insights into eruption precursors at Volcán de Colima. Geophysical Research Letters 44, 6092-6100. doi:10.1002/ 2017 GL073350.

Lamb, O.D., Lees, J., Marin, L.F., Lazo, J., Rivera, A., Shore, M., Lee, S., 2020. Investigating potential icequakes at Llaima volcano, Chile. Volcanica 3,29-42. doi:10.30909/vol.03.01.2942.

Leet, R.C., 1988. Saturated and subcooled hydrothermal boiling in groundwater flow channels as a source of harmonic tremor. Journal of Geophysical Research: Solid Earth 93, 4835-4849. doi:10.1029/ JB093iB05p04835.

de Maisonneuve, C.B., Dungan, M.A., Bachmann, O., Burgisser, A., 2012. Insights into shallow magma storage and crystallization at Volcán Llaima (Andean Southern Volcanic Zone, Chile). Journal of Volcanology and Geothermal Research 211-212, 76-91. doi:https://doi.org/10.1016/j. jvolgeores.2011.09.010.

Matoza, R.S., Chouet, B.A., Dawson, P.B., Shearer, P.M., Haney, M.M., Waite, G.P., Moran, S.C., Mikesell, T.D., 2015. Source mechanism of small long-period events at Mount St. Helens in July 2005 using template matching, phase-weighted stacking, and full-waveform inversion. Journal of Geophysical Research: Solid Earth 120,6351-6364. doi:10 . 1002 / 2015 JB012279.

Matthews, A.J., Barclay, J., Johnstone, J.E., 2009. The fast response of volcano-seismic activity to intense precipitation: Triggering of primary volcanic activity by rainfall at Soufrière Hills Volcano, Montserrat. Journal of Volcanology and Geothermal Research 184, 405-415. doi:10.1016/j.jvolgeores . 2009.05 .010$.

Mikesell, T.D., Wijk, K.V., Haney, M.M., Bradford, J.H., Marshall, H.P., Harper, J.T., 2012. Monitoring glacier surface seismicity in time and space using Rayleigh waves. Journal of Geophysical Research 117, 1-12. doi:10.1029/2011JF002259.

Mora-Stock, C., Thorwart, M., Wunderlich, T., Bredemeyer, S., Hansteen, T.H., Rabbel, W., 2014. Comparison of seismic activity for Llaima and Villarrica volcanoes prior to and after the Maule 2010 earthquake 103, 2015-2028. doi:10.1007/s00531-012-0840-x.

Métaxian, J.P., Araujo, S., Mora, M.M., Lesage, P., 2003. Seismicity related to the glacier of Cotopaxi Volcano, Ecuador. Geophysical Research Letters 30,1-4. doi:10.1029/2002GL016773. 
Nanni, U., Gimbert, F., Vincent, C., Gräff, D., Walter, F., Piard, L., Moreau, L., 2020. Quantification of seasonal and diurnal dynamics of subglacial channels using seismic observations on an Alpine glacier. The Cryosphere 14, 1475-1496. doi:10.5194/tc-14-1475-2020.

Naranjo, J.A., Moreno, H., 2005. Geología del Volcán Llaima. Carta Geológica de Chile - Serie Geología Básica 88, 1-37.

Park, I., Jolly, A., Kim, K.Y., Kennedy, B., 2019. Temporal variations of repeating low frequency volcanic earthquakes at Ngauruhoe Volcano, New Zealand. Journal of Volcanology and Geothermal Research 373, 108-119. doi:10.1016/j.jvolgeores.2019.01.024.

Podolskiy, E.A., Walter, F., 2016. Cryoseismology. Reviews of Geophysics S4, 708-758. doi:10 . 1002 / 2016RG000526.

Reinthaler, J., Paul, F., Granados, H.D., Rivera, A., Huggel, C., 2019. Area changes of glaciers on active volcanoes in Latin America between 1986 and 2015 observed from multi-temporal satellite imagery. Journal of Glaciology , 1-15doi:10.1017/ jog.2019.30.

Roeoesli, C., Helmstetter, A., Walter, F., Kissling, E., 2016. Meltwater influences on deep stick-slip icequakes near the base of the Greenland Ice Sheet. Journal of Geophysical Research: Earth Surface 121, 223-240. doi:10.1002/2015 JF003601.

Ruth, D.C.S., Costa, F., Bouvet de Maisonneuve, C., Franco, L., Cortés, J.A., Calder, E.S., 2018. Crystal and melt inclusion timescales reveal the evolution of magma migration before eruption. Nature Communications 9, 2657. doi:10.1038/s41467-018-05086-8.

Ruth, D.C.S., Cottrell, E., Calder, E.S., Cortés, J.A., Kelley, K.A., 2016. From Passive Degassing to Violent Strombolian Eruption: the Case of the 2008 Eruption of Llaima Volcano, Chile. Journal of Petrology 57, 1833-1864. doi:10.1093/petrology/egw063.

Senobari, N.S., Funning, G.J., Keogh, E., Zhu, Y., Yeh, C.M., Zimmerman, Z., Mueen, A., 2019. SuperEfficient Cross-Correlation (SEC-C): A Fast Matched Filtering Code Suitable for Desktop Computers. Seismological Research Letters 90,322-334. doi:10 .1785/0220180122.

Thelen, W.A., Allstadt, K.E., De Angelis, S., Malone, S.D., Moran, S.C., Vidale, J., 2013. Shallow repeating seismic events under an alpine glacier at Mount Rainier, Washington, USA. Journal of Glaciology 59, 345-356. doi:10 . 3189/2013 JoG12 J111.

Venzke, E., 2013. Global Volcanism Program. doi:10 . 5479/si . GVP . VOTW4-2013.

Weaver, C.S., Malone, S.D., 1976. Mt. Saint Helens Seismic Events: Volcanic Earthquakes or Glacial Noises? Geophysical Research Letters 3, 197-200.

Wech, A.G., Creager, K.C., 2008. Automated detection and location of Cascadia tremor. Geophysical Research Letters 35, L20302. doi:10 . 1029/2008GL035458. 


\section{Supplementary Material:}

\section{Persistent shallow micro-seismicity at Llaima volcano, Chile, with implications for long-term monitoring}

\section{TABLES}

Table S1. Details of the stations used in this study, including the site correction factors. Type indicates if station included a short-period (SP) and broad-band (BB) seismometer.

\begin{tabular}{c|c|c|c|c|c} 
Station Name & Longitude & Latitude & Elevation [m a.s.l.] & Type & Site Corr. \\
\hline \hline AGU & -71.715 & -38.723 & 2140 & BB & 1.574 \\
\hline CON & -71.771 & -38.74 & 1757 & BB & 1.063 \\
\hline CRU & -71.7995 & -38.709 & 1694 & BB & 0.639 \\
\hline MO2 & -71.784 & -38.675 & 1605 & BB & 1 \\
\hline LAJ & -71.696 & -38.755 & 1565 & SP & 0.293 \\
\hline LAV & -71.646 & -38.702 & 1077 & BB & 1.190 \\
\hline LLA & -71.7 & -38.781 & 1081 & BB & 0.351 \\
\hline PIC & -71.726 & -38.706 & 2891 & SP & 0.868 \\
\hline
\end{tabular}

Table S2. Details of the located earthquakes detected by OVDAS used for qualitative magnitude estimates. Distances from Llaima are calculated from the summit of the volcano.

\begin{tabular}{c|c|c|c|c|c} 
Event time [UTC] & Latitude & Longitude & Depth $[\mathrm{km}]$ & Dist. from Llaima $[\mathrm{km}]$ & Magnitude $\left[\mathrm{M}_{l}\right]$ \\
\hline \hline $03 / 02 / 201903: 30: 10$ & -38.820 & -71.697 & 12.83 & 13.99 & 0.9 \\
\hline $05 / 02 / 201904: 24: 03$ & -38.703 & -71.739 & 1.11 & 0.98 & 1.7 \\
\hline $09 / 02 / 201911: 02: 31$ & -38.668 & -71.556 & 12.77 & 15.40 & 0.5 \\
\hline $14 / 02 / 201904: 25: 17$ & -38.672 & -71.566 & 12.02 & 14.42 & 0.7 \\
\hline $10 / 03 / 201917: 15: 03$ & -38.772 & -71.733 & 3.37 & 8.22 & 1.6 \\
\hline $13 / 03 / 201901: 32: 09$ & -38.855 & -71.756 & 8.14 & 17.64 & 2.6 \\
\hline $17 / 03 / 201900: 10: 05$ & -38.856 & -71.735 & 12.76 & 17.58 & 1.1 \\
\hline $17 / 03 / 201902: 39: 58$ & -38.702 & -71.728 & 0.96 & 0.63 & 1.4 \\
\hline $24 / 03 / 201917: 18: 48$ & -38.813 & -71.786 & 7.97 & 13.75 & 0.7 \\
\hline
\end{tabular}


Table S3. Details of the regional earthquakes detected by Centro Sismológico Nacional used for qualitative magnitude estimates. Distances from Llaima are calculated from the summit of the volcano.

\begin{tabular}{l|l|l|l|l|l|l|} 
Event time [UTC] & Latitude & Longitude & Depth [km] & Dist. from Llaima [km] & Magnitude $\left[\mathrm{M}_{l}\right]$ \\
\hline
\end{tabular}

\begin{tabular}{c|c|c|c|c|c}
\hline \hline $18 / 02 / 201920: 17: 13$ & -39.572 & -72.493 & 76 & 117.46 & 3.0 \\
\hline $19 / 02 / 201901: 53: 17$ & -36.973 & -72.855 & 30.8 & 215.66 & 2.6 \\
\hline $20 / 02 / 201912: 08: 00$ & -37.335 & -73.125 & 51.3 & 194.60 & 3.1 \\
\hline $20 / 02 / 201912: 08: 02$ & -37.348 & -72.966 & 20 & 105.62 & 3.1 \\
\hline $20 / 02 / 201907: 59: 45$ & -37.938 & -72.458 & 46.2 & 129.25 & 2.6 \\
\hline $21 / 02 / 201923: 25: 00$ & -37.604 & -72.233 & 75.7 & 119.62 & 3.3 \\
\hline $22 / 02 / 201920: 28: 39$ & -37.765 & -71.046 & 2.2 & 249.04 & 3.1 \\
\hline $22 / 02 / 201914: 39: 40$ & -37.519 & -74.151 & 38.7 & 114.28 & 2.8 \\
\hline $22 / 02 / 201907: 13: 46$ & -37.794 & -71.105 & 20.6 & 114.59 & 3.0 \\
\hline $23 / 02 / 201909: 16: 22$ & -37.773 & -71.149 & 20.4 & 190.36 & 3.3 \\
\hline $24 / 02 / 201908: 49: 16$ & -37.962 & -73.701 & 39.7 & 168.69 & 2.7 \\
\hline $24 / 02 / 201900: 27: 51$ & -39.054 & -73.624 & 37.5 & 154.34 & 3.6 \\
\hline $26 / 02 / 201911: 40: 23$ & -40.066 & -72.026 & 113.1 & 200.20 & 3.7 \\
\hline $26 / 02 / 201900: 59: 09$ & -40.246 & -72.919 & 61.4 & 119.48 & 3.3 \\
\hline $02 / 03 / 201921: 17: 51$ & -37.771 & -71.036 & 1.8 & 192.59 & 2.8 \\
\hline $02 / 03 / 201902: 32: 32$ & -38.219 & -73.856 & 28 & 219.97 & 3.0 \\
\hline $02 / 03 / 201902: 29: 49$ & -38.207 & -73.832 & 25.7 & 206.92 & 3.2 \\
\hline $06 / 03 / 201918: 07: 11$ & -40.602 & -72.402 & 103.2 & 93.05 & 3.3 \\
\hline $07 / 03 / 201911: 55: 17$ & -36.847 & -71.984 & 79.4 & 151.87 & 2.6 \\
\hline $13 / 03 / 201903: 10: 10$ & -39.479 & -72.114 & 101.8 & 85.39 & 2.7 \\
\hline $17 / 03 / 201910: 28: 20$ & -37.417 & -72.335 & 99.3 & 86.69 & 2.7 \\
\hline $19 / 03 / 201923: 34: 22$ & -39.245 & -72.422 & 25 & 178.50 & 3.0 \\
\hline $19 / 03 / 201923: 27: 36$ & -39.238 & -72.452 & 25.4 & 211.59 & 3.0 \\
\hline $20 / 03 / 201923: 09: 47$ & -38.528 & -73.773 & 25.5 & 110.27 & 2.6 \\
\hline $20 / 03 / 201902: 33: 28$ & -37.929 & -73.949 & 22.3 & 165.71 & 4.0 \\
\hline $25 / 03 / 201916: 32: 59$ & -39.542 & -72.399 & 87.8 & & 2.5 \\
\hline $26 / 03 / 201921: 47: 42$ & -37.739 & -73.183 & 24.7 & & \\
\hline
\end{tabular}




\section{FIGURES}
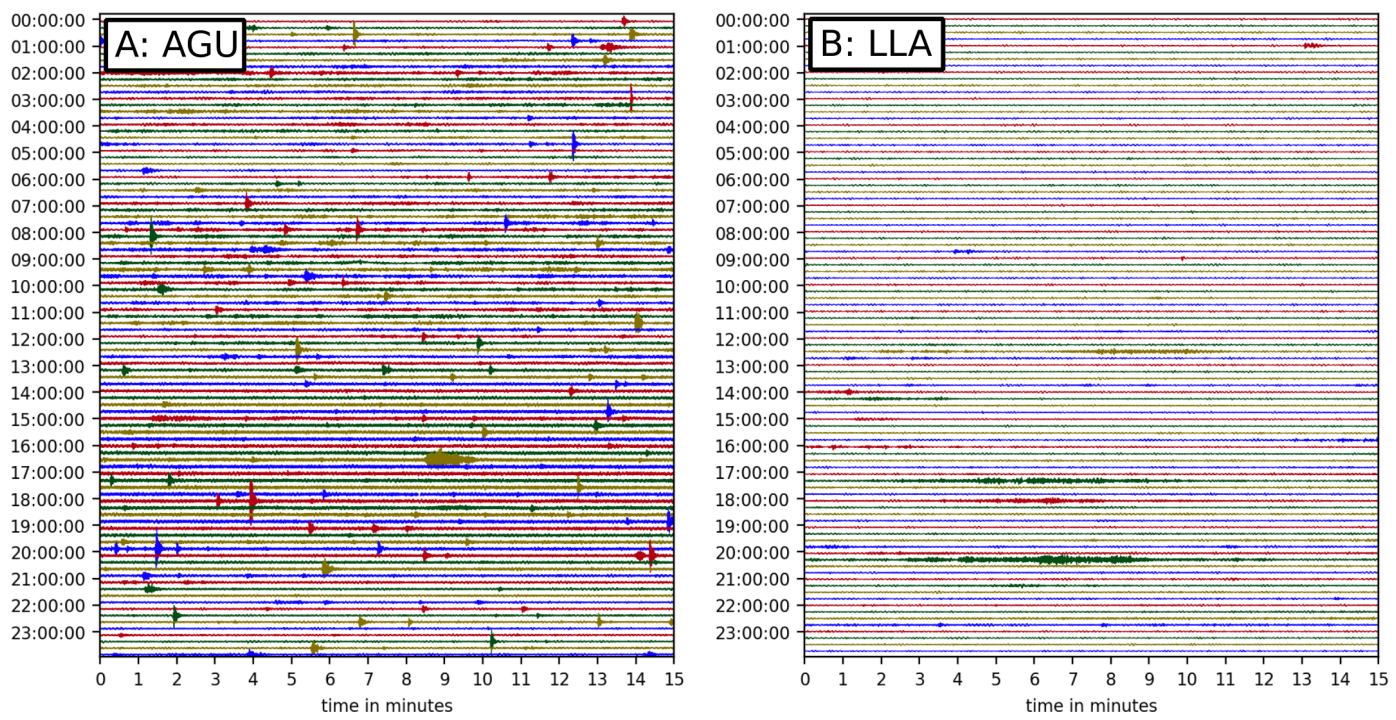

Figure S1. 24 hours of seismic data as recorded by stations AGU (A) and LLA (B) on 22 March 2019. Each horizontal line is 15 minutes of seismic data. Time y-axis is UTC.

OVDAS catalog for Llaima - events manually catalogued per $6 \mathrm{hr}$

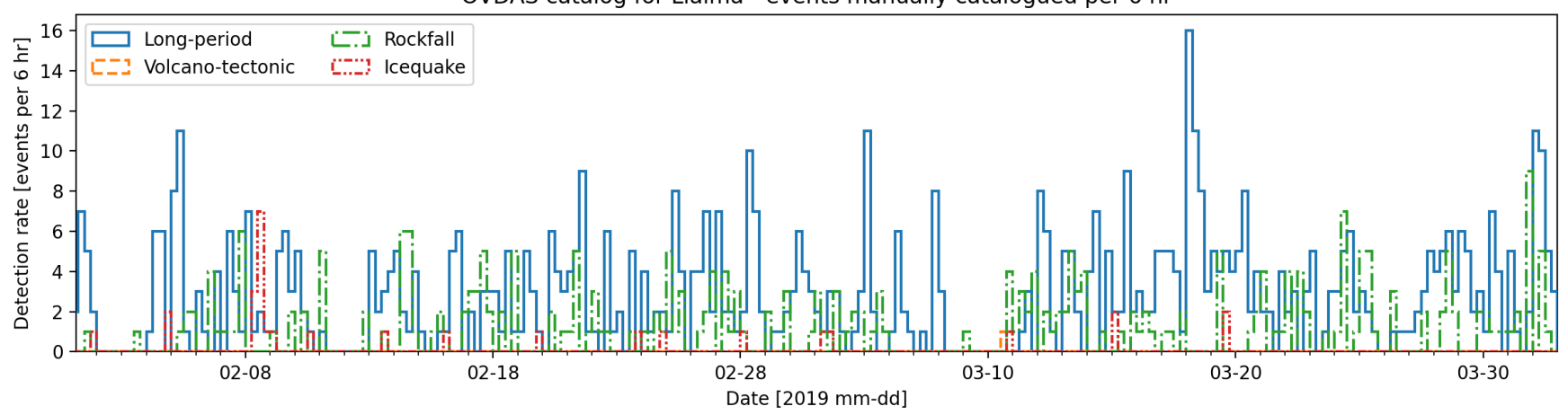

Figure S2. Histogram of seismic events at Llaima volcano from 1 February to 1 April 2019 as manually catalogued by OVDAS. 


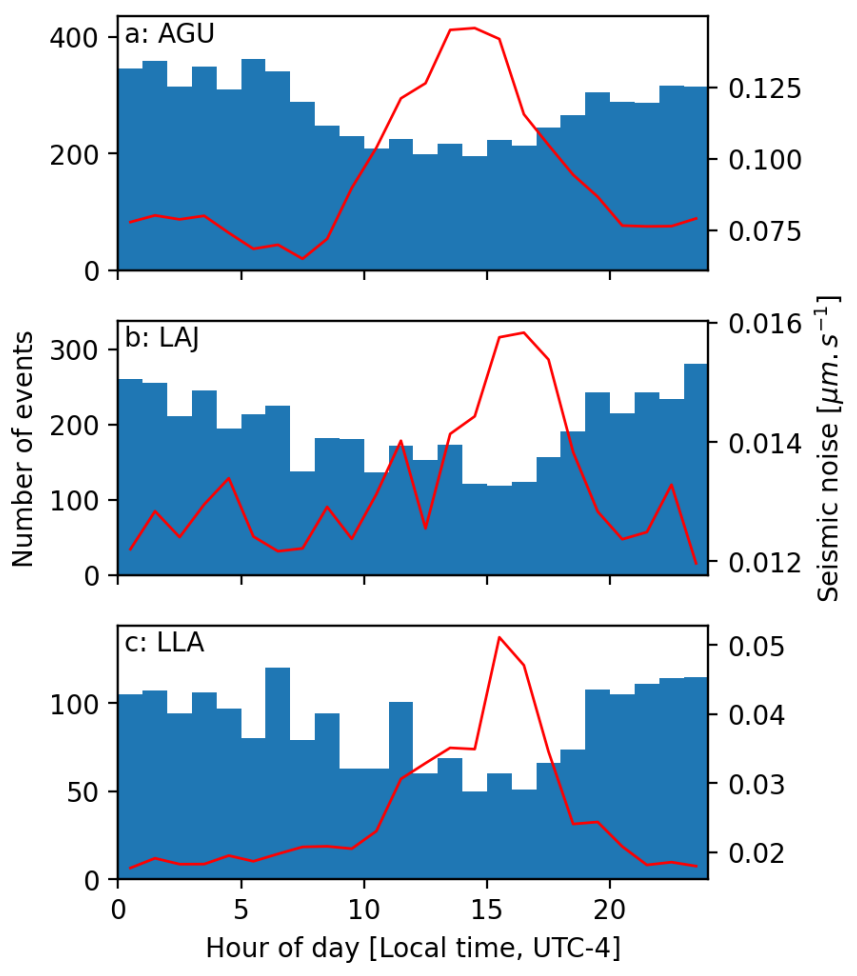

Figure S3. Histogram of detected event times binned by hour of day (local time, UTC-4) with mean seismic noise in a $15 \mathrm{~s}$ window preceding each trigger detected within each hour, for stations (a) AGU, (b) LAJ and (c) LLA. See Fig. 11 in main text for locations of each station. 

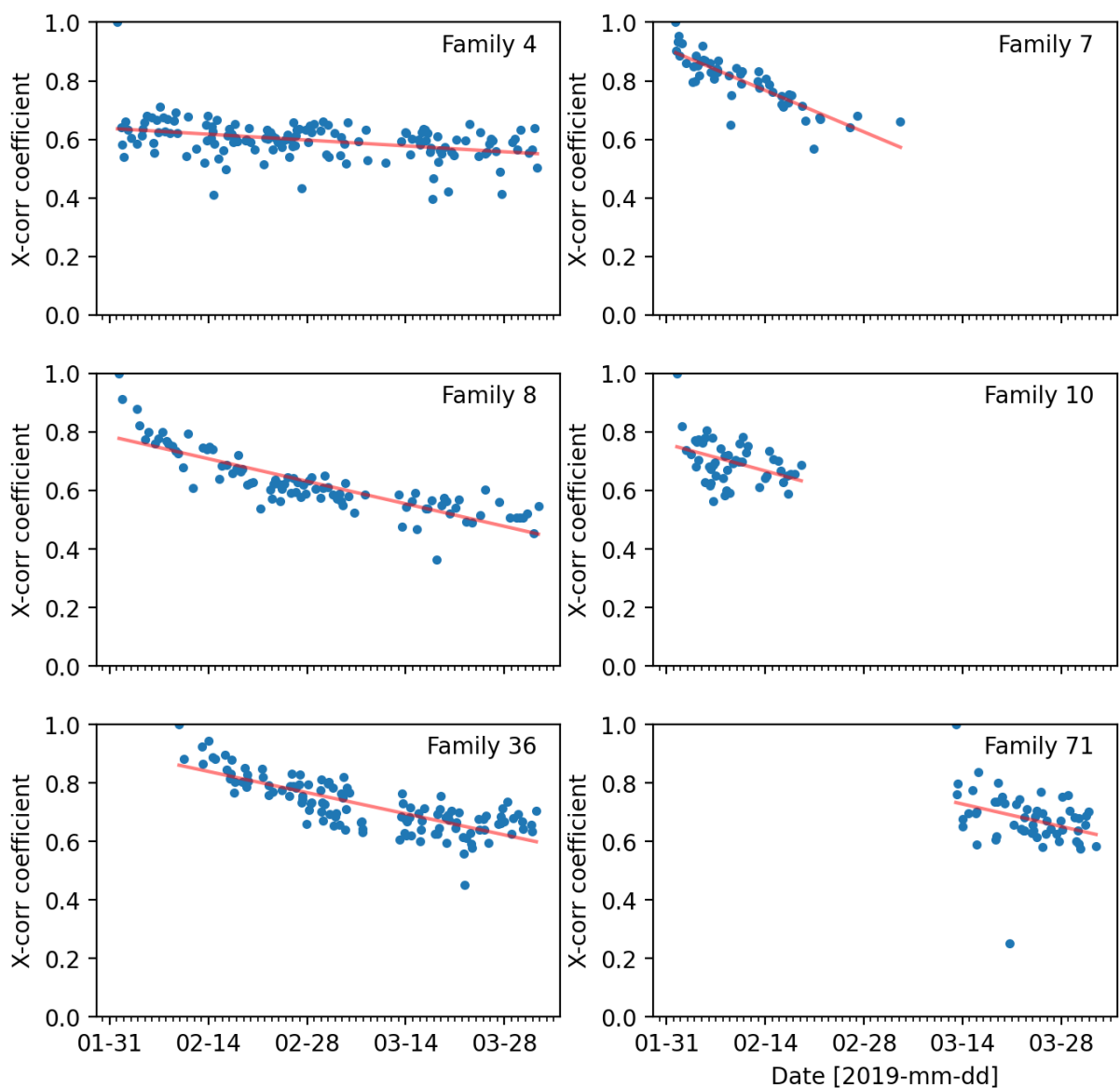

Figure S4. Cross-correlation coefficients of individual events within a selection of families, with respect to the first event within each family. Also plotted are red lines of linear regression estimated from all cross-correlation values within each family. 


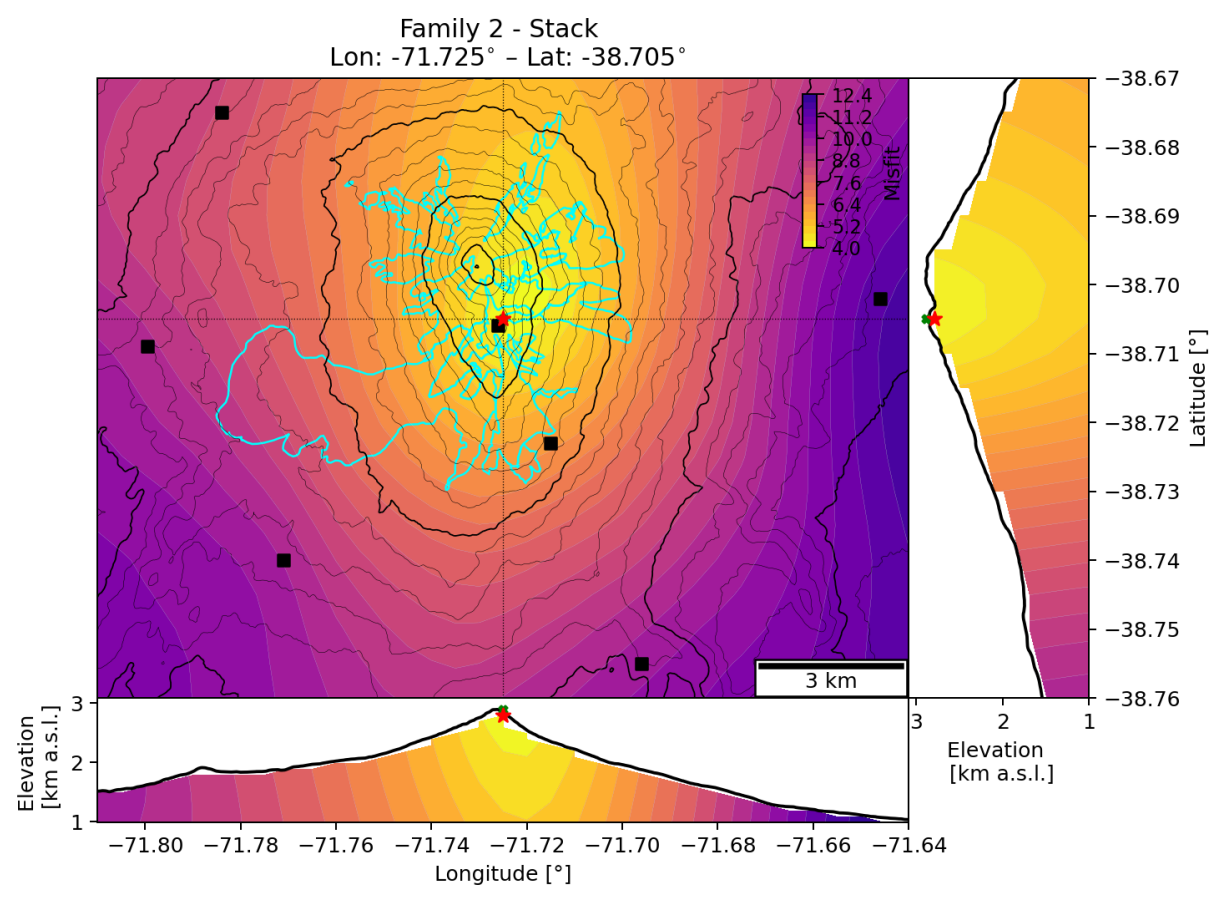

Figure S5. Example output of location method used, here illustrating the location of Family 2 (red star). The green square in each cross section panel (right and bottom) shows the location if topography was not accounted for. Each cross section profile is located through the final location of the family. Blue lines on main panel outline the mapped summit glacial areas. Black squares are locations of OVDAS seismic stations.

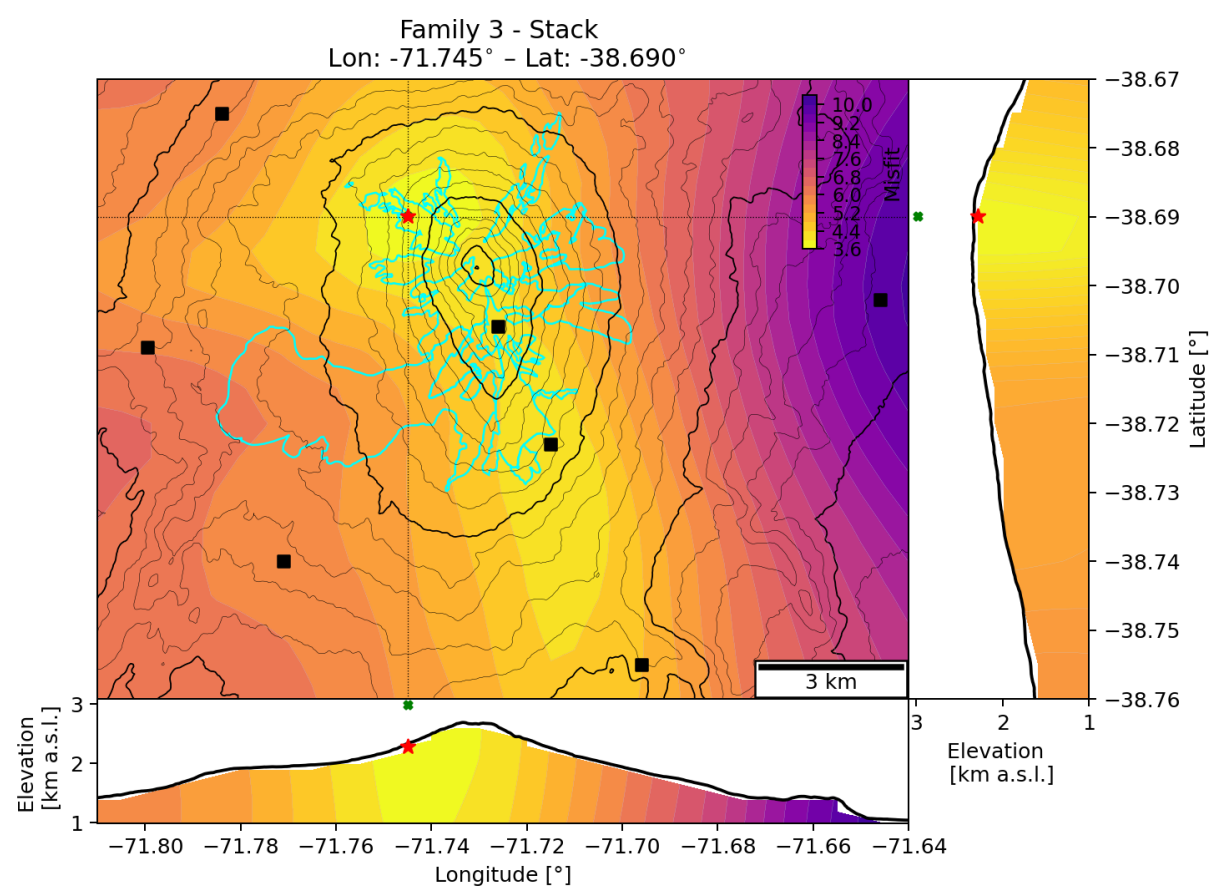

Figure S6. Location of Family 3. See caption of Fig. S5 for details. 


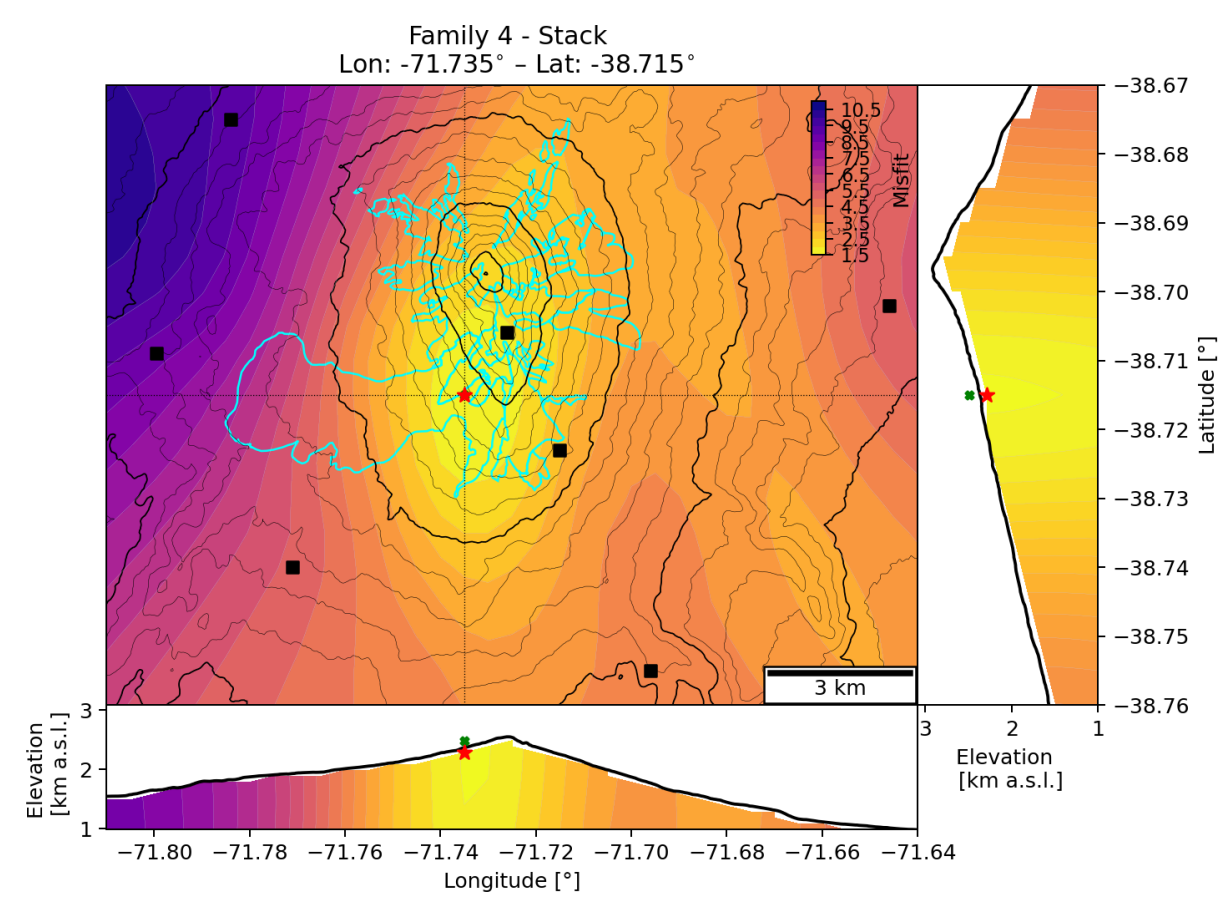

Figure S7. Location of Family 4. See caption of Fig. S5 for details.

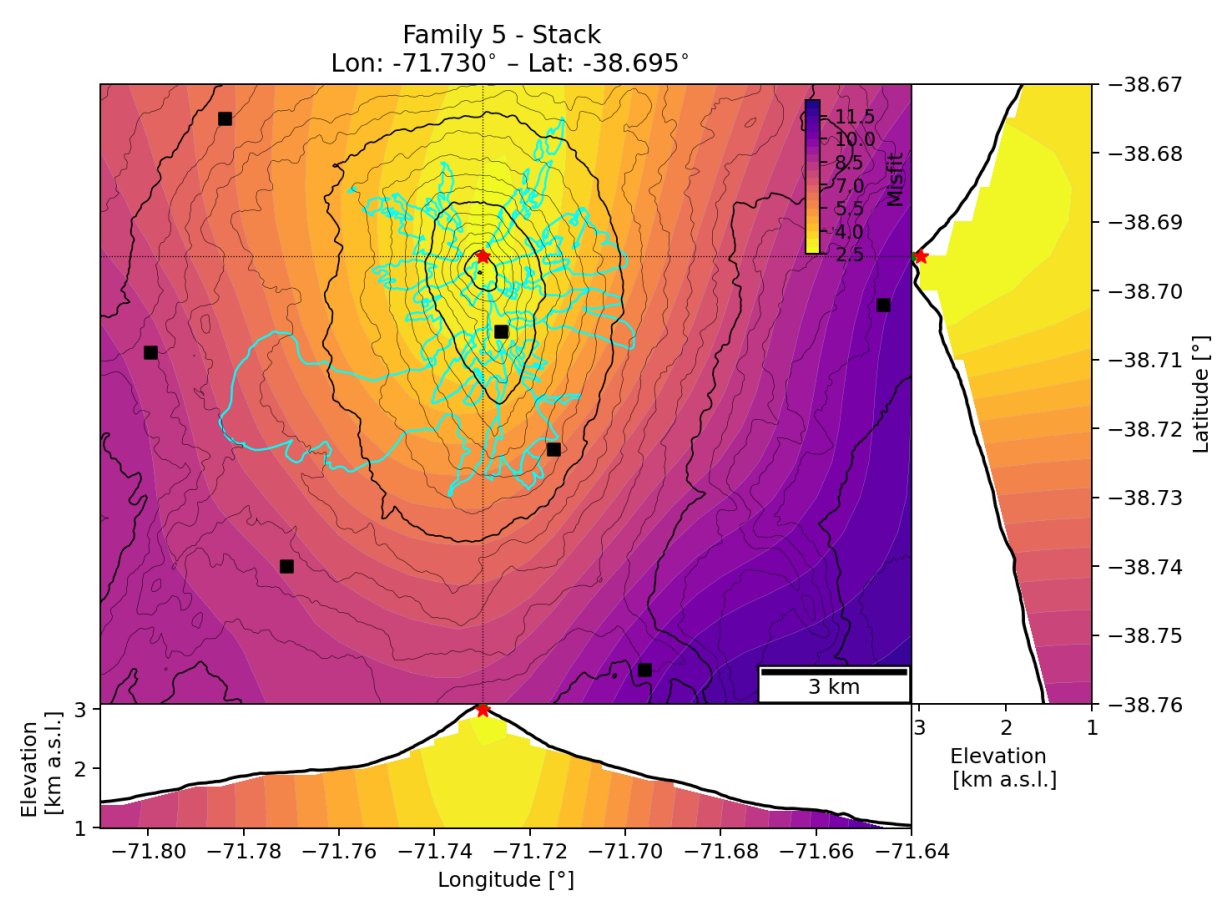

Figure S8. Location of Family 5. See caption of Fig. S5 for details. 


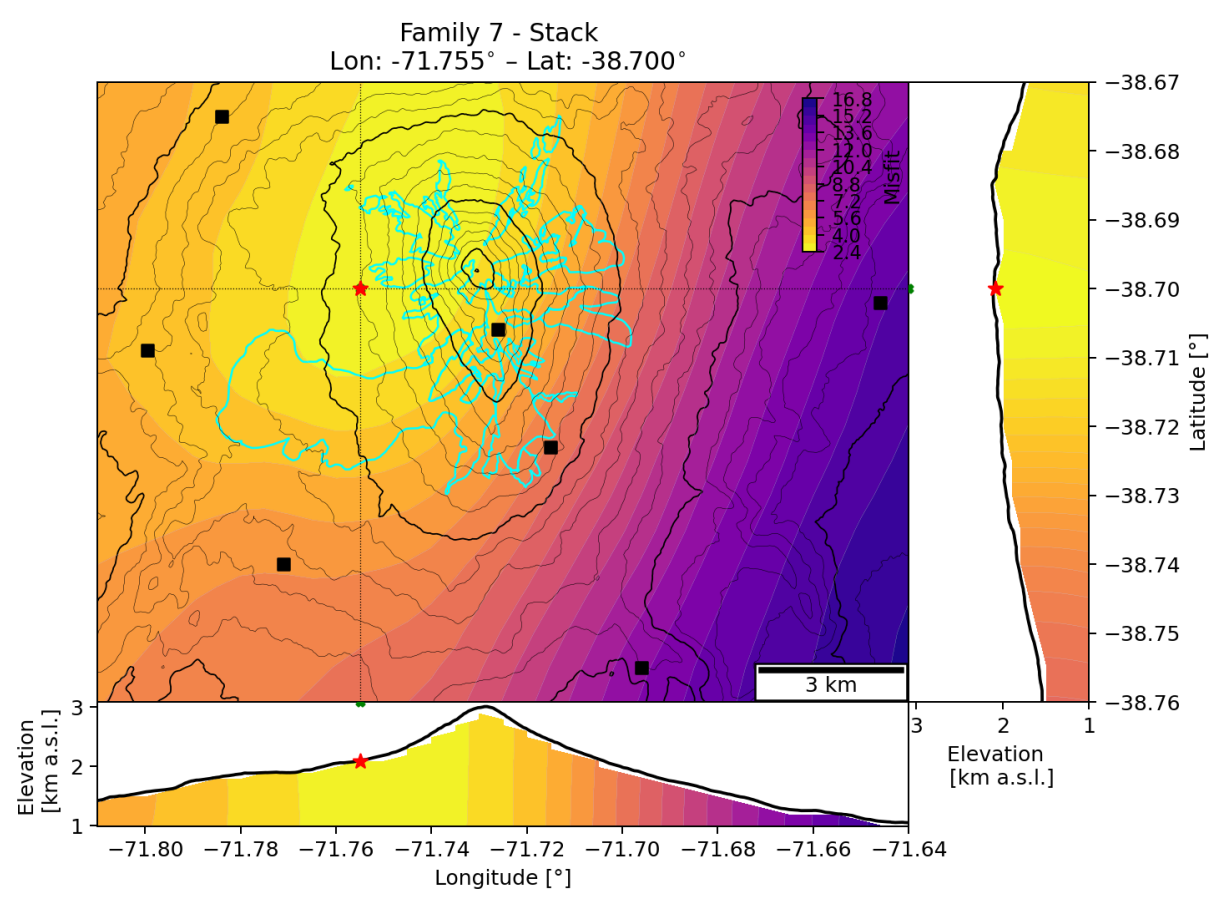

Figure S9. Location of Family 7. See caption of Fig. S5 for details.

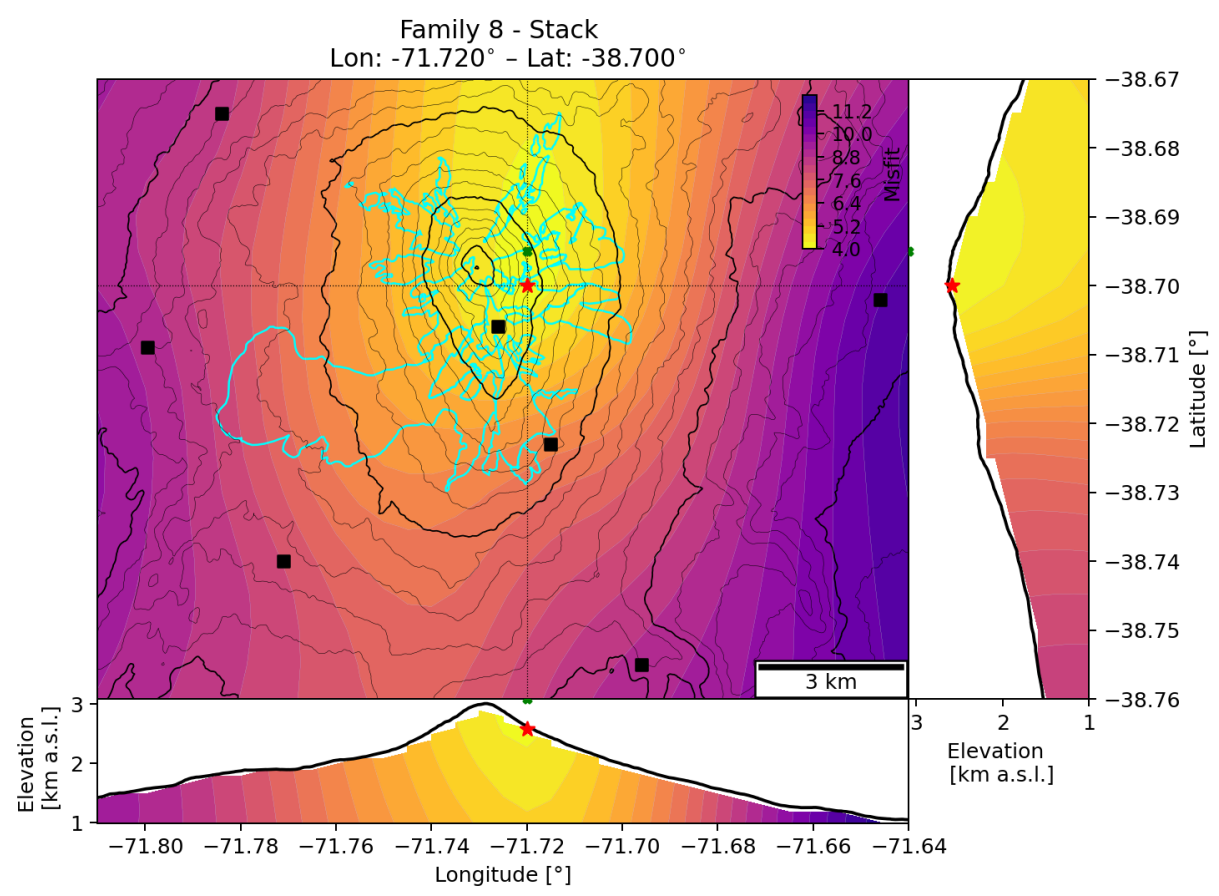

Figure S10. Location of Family 8. See caption of Fig. S5 for details. 


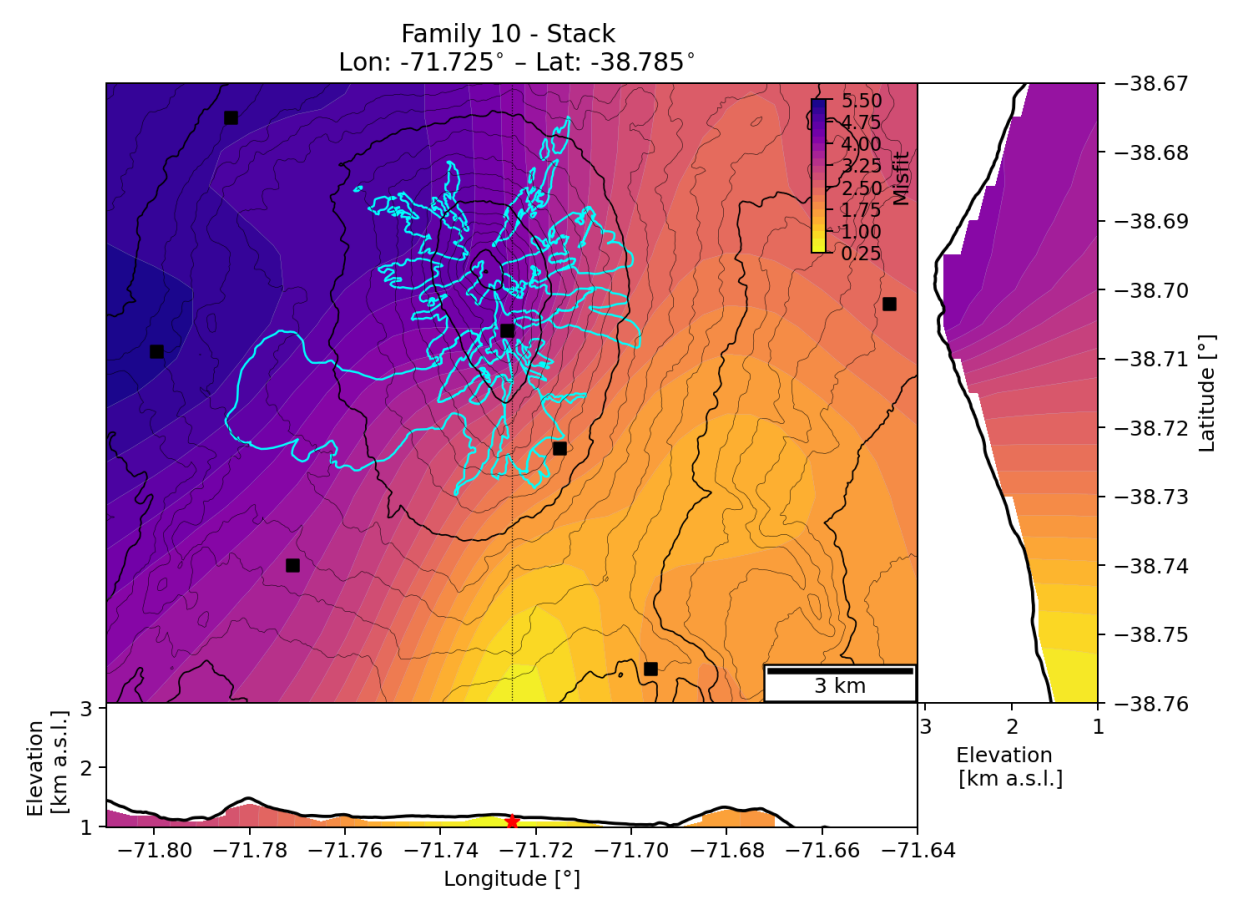

Figure S11. Location of Family 10, which was too close to edge to be considered. See caption of Fig. S5 for details.

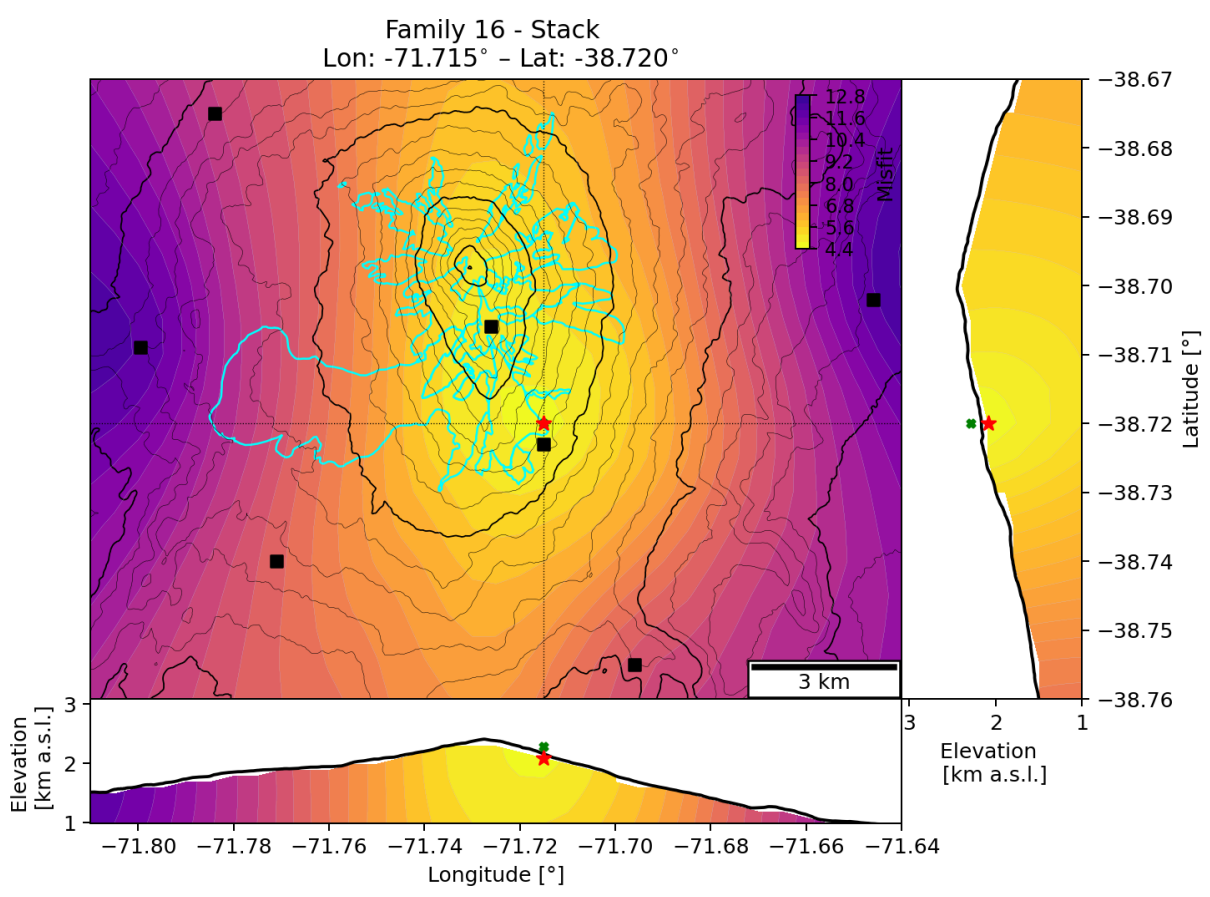

Figure S12. Location of Family 16. See caption of Fig. S5 for details. 


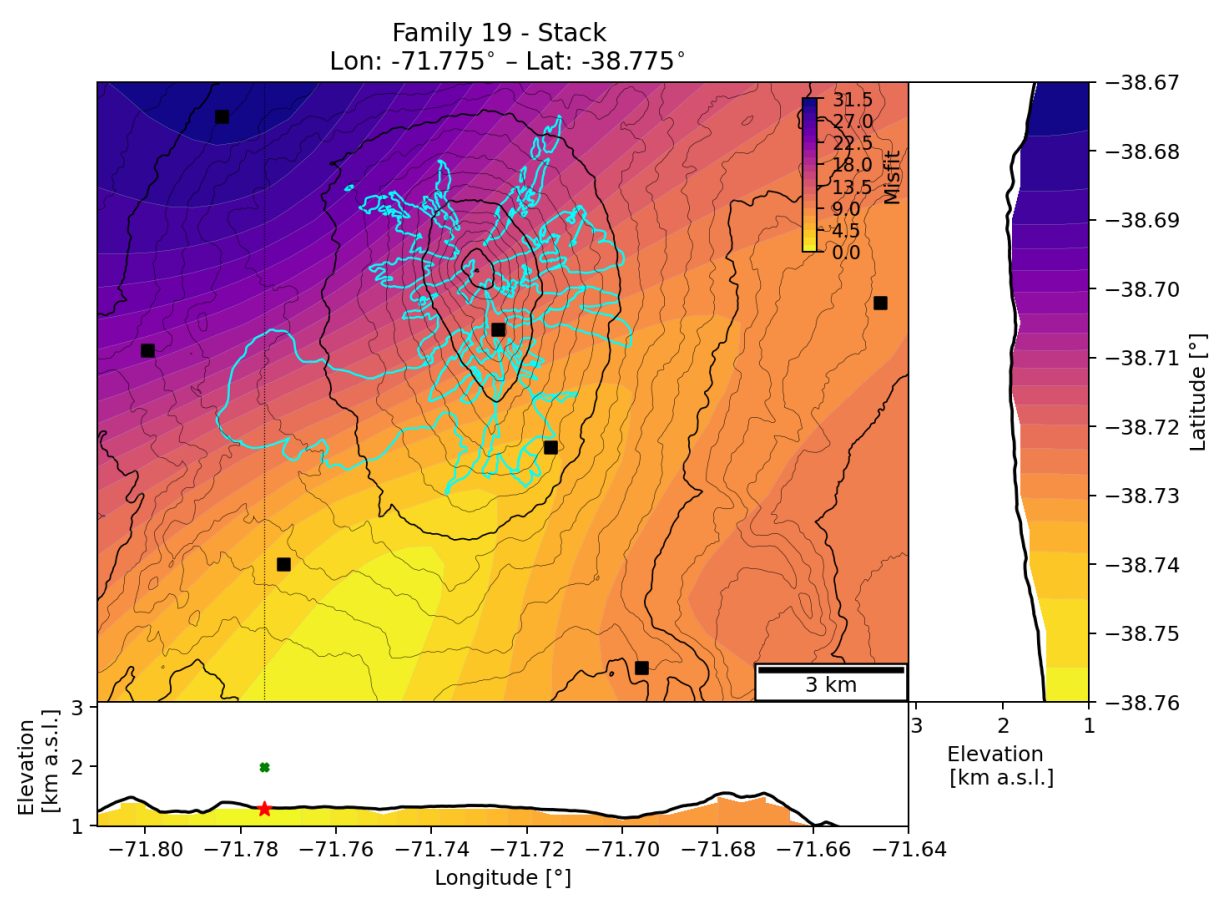

Figure S13. Location of Family 19, which was too close to edge to be considered. See caption of Fig. S5 for details.

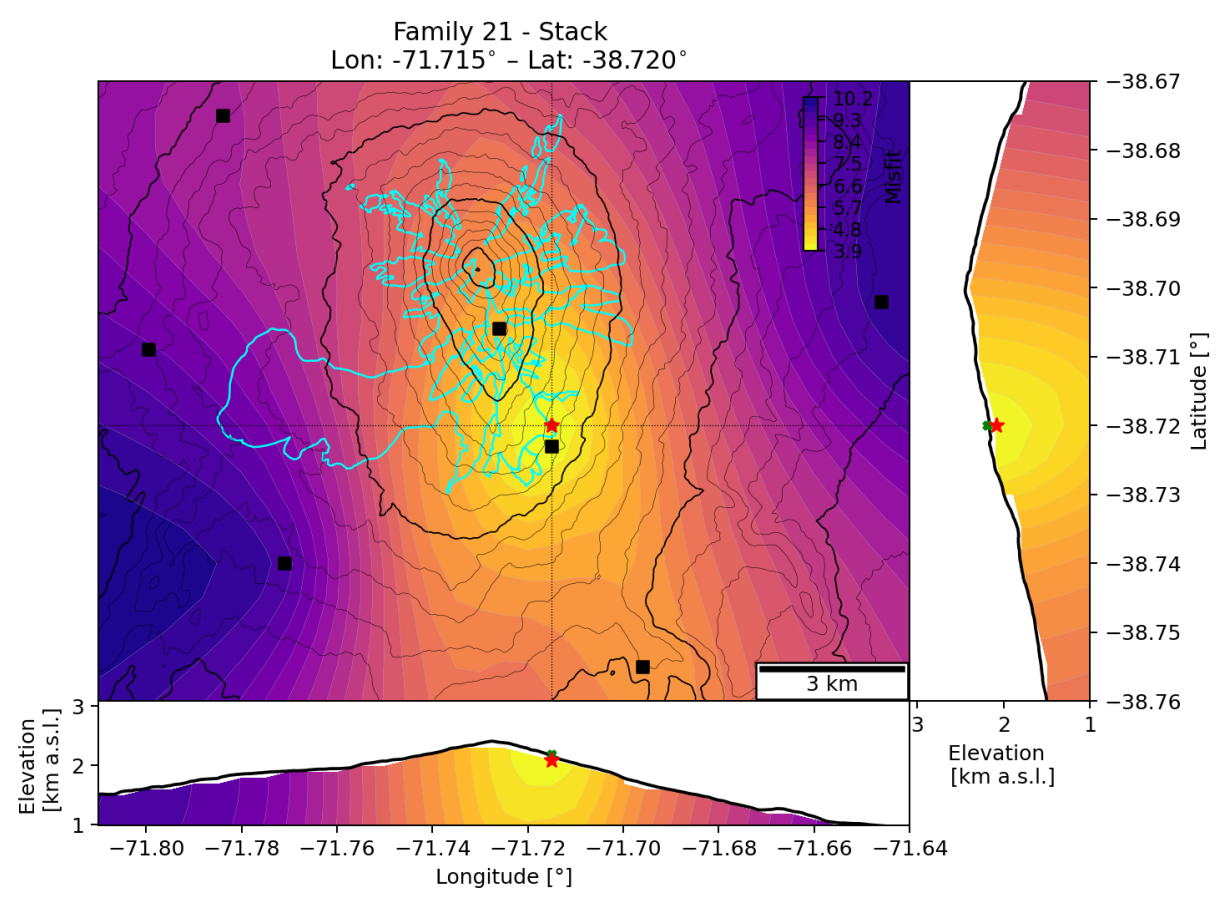

Figure S14. Location of Family 21. See caption of Fig. S5 for details. 


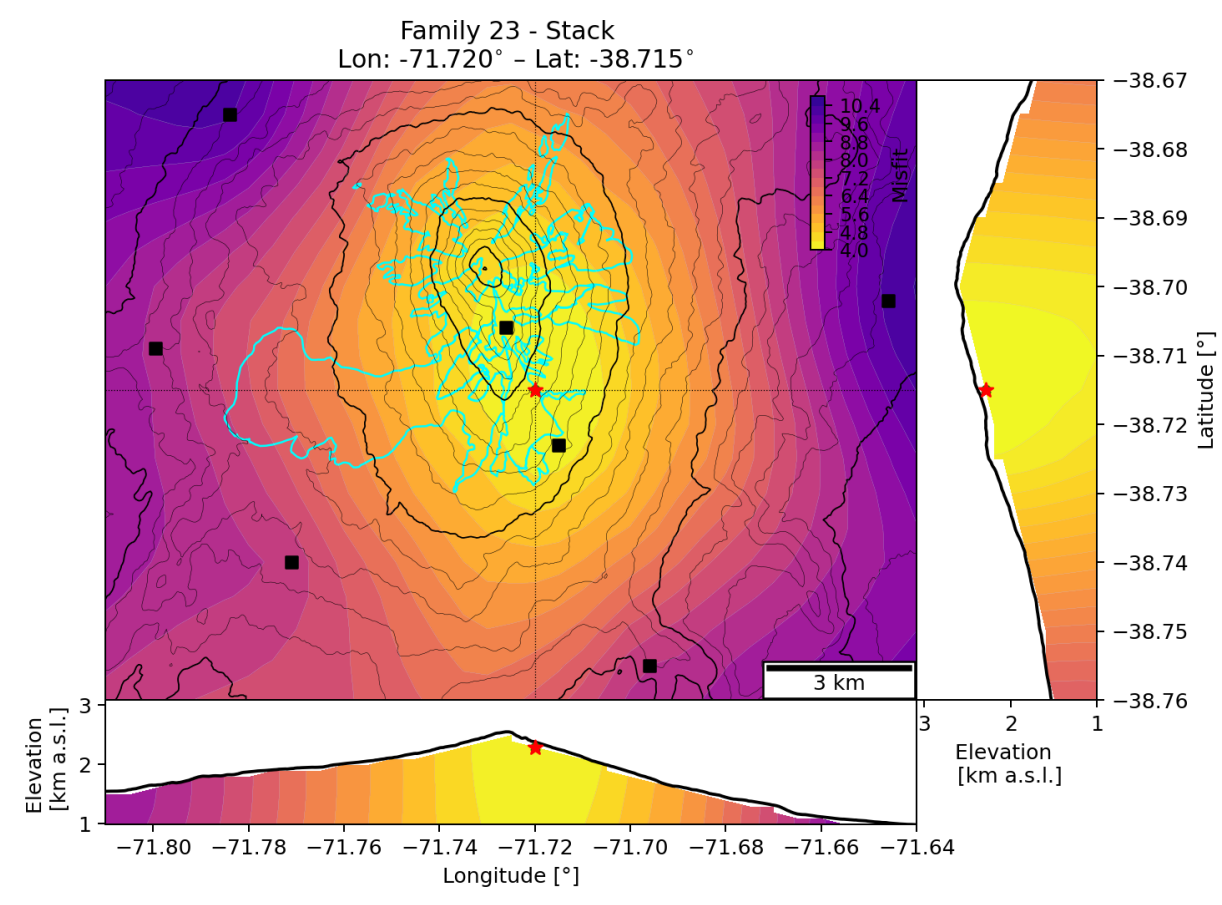

Figure S15. Location of Family 23. See caption of Fig. S5 for details.

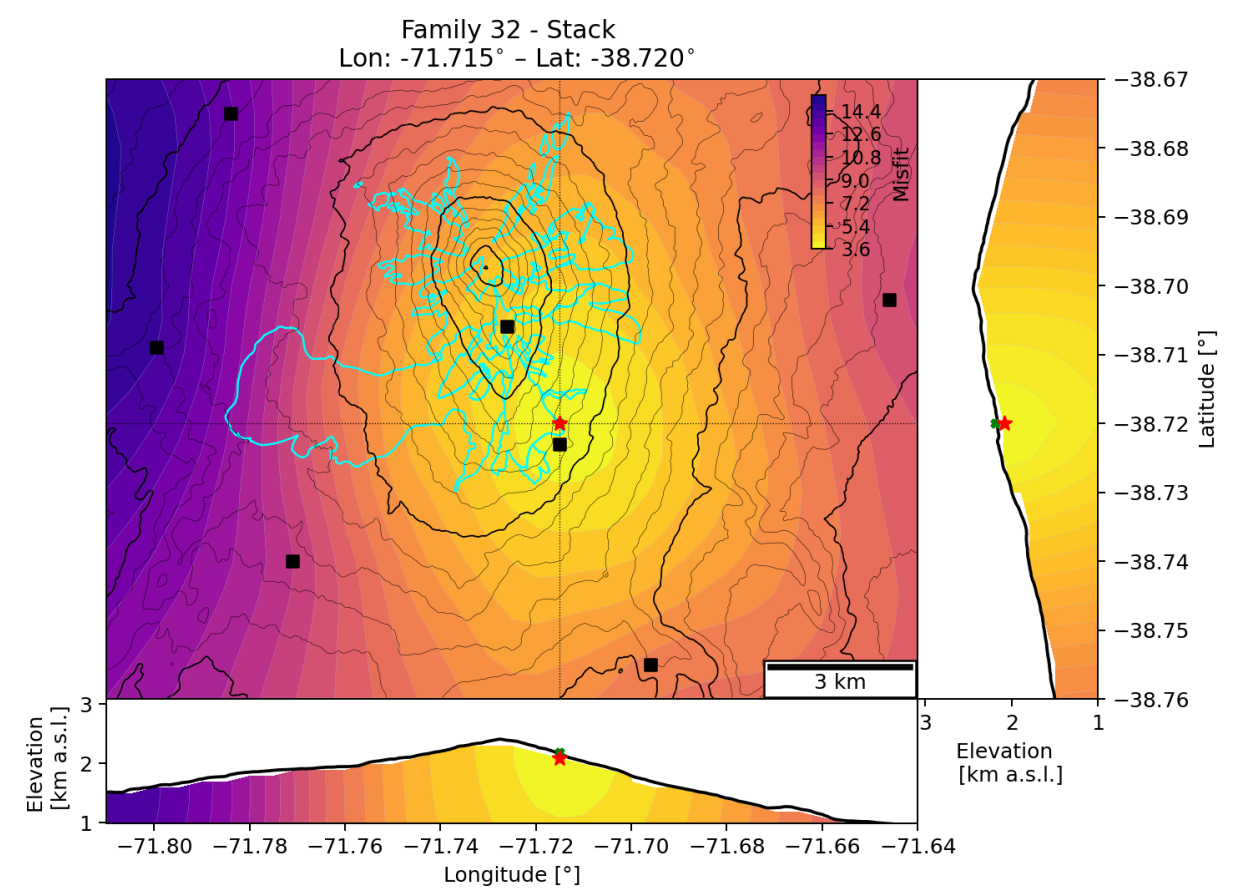

Figure S16. Location of Family 32. See caption of Fig. S5 for details. 


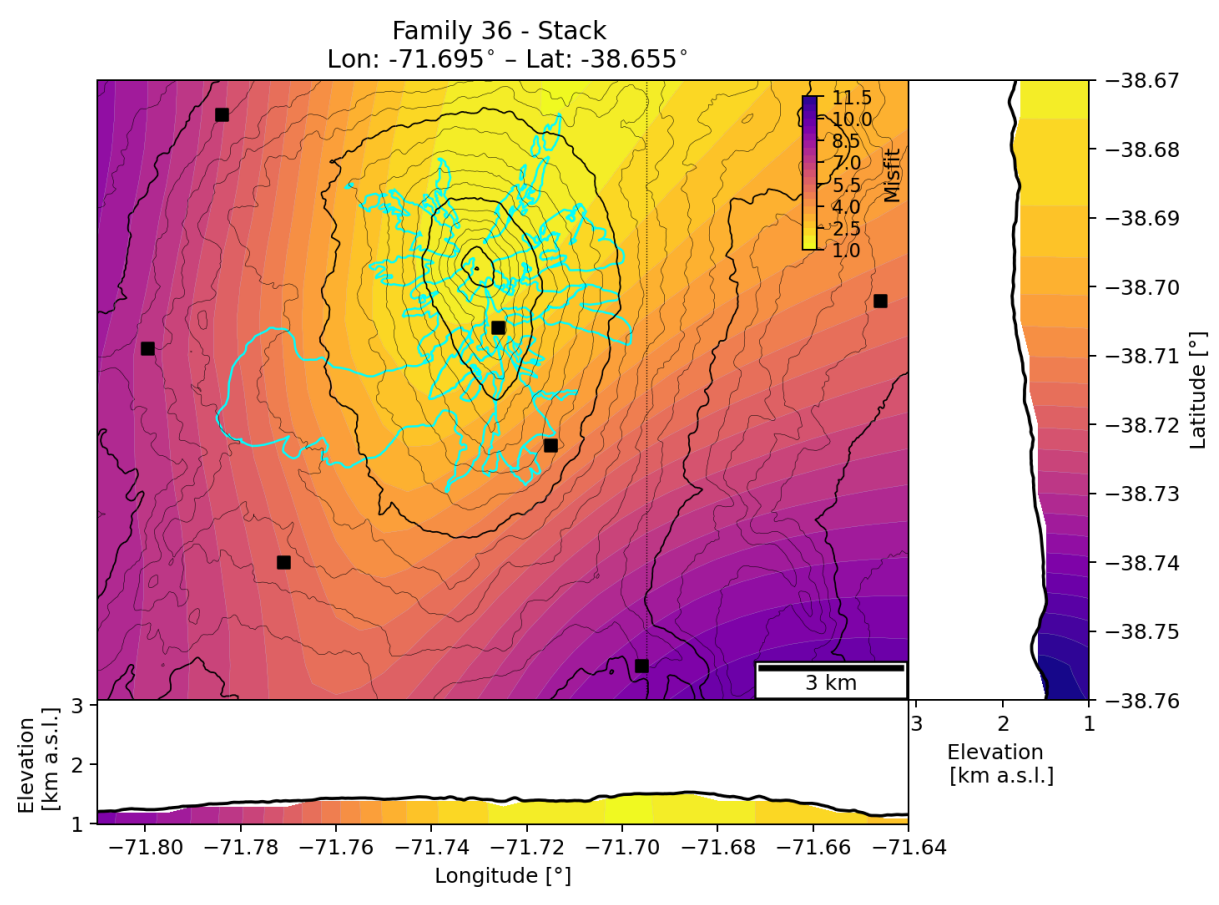

Figure S17. Location of Family 36, which was too close to edge to be considered. See caption of Fig. S5 for details.

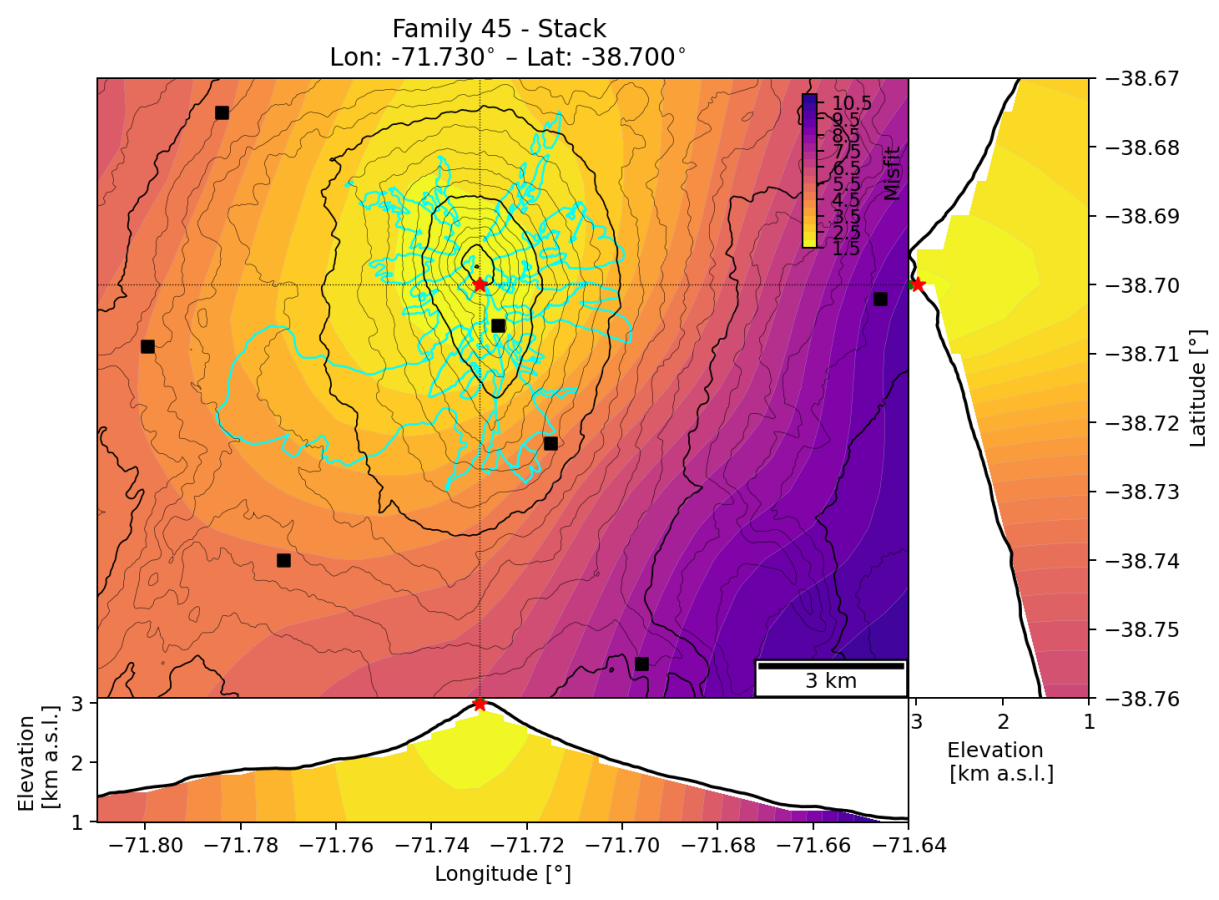

Figure S18. Location of Family 45. See caption of Fig. S5 for details. 


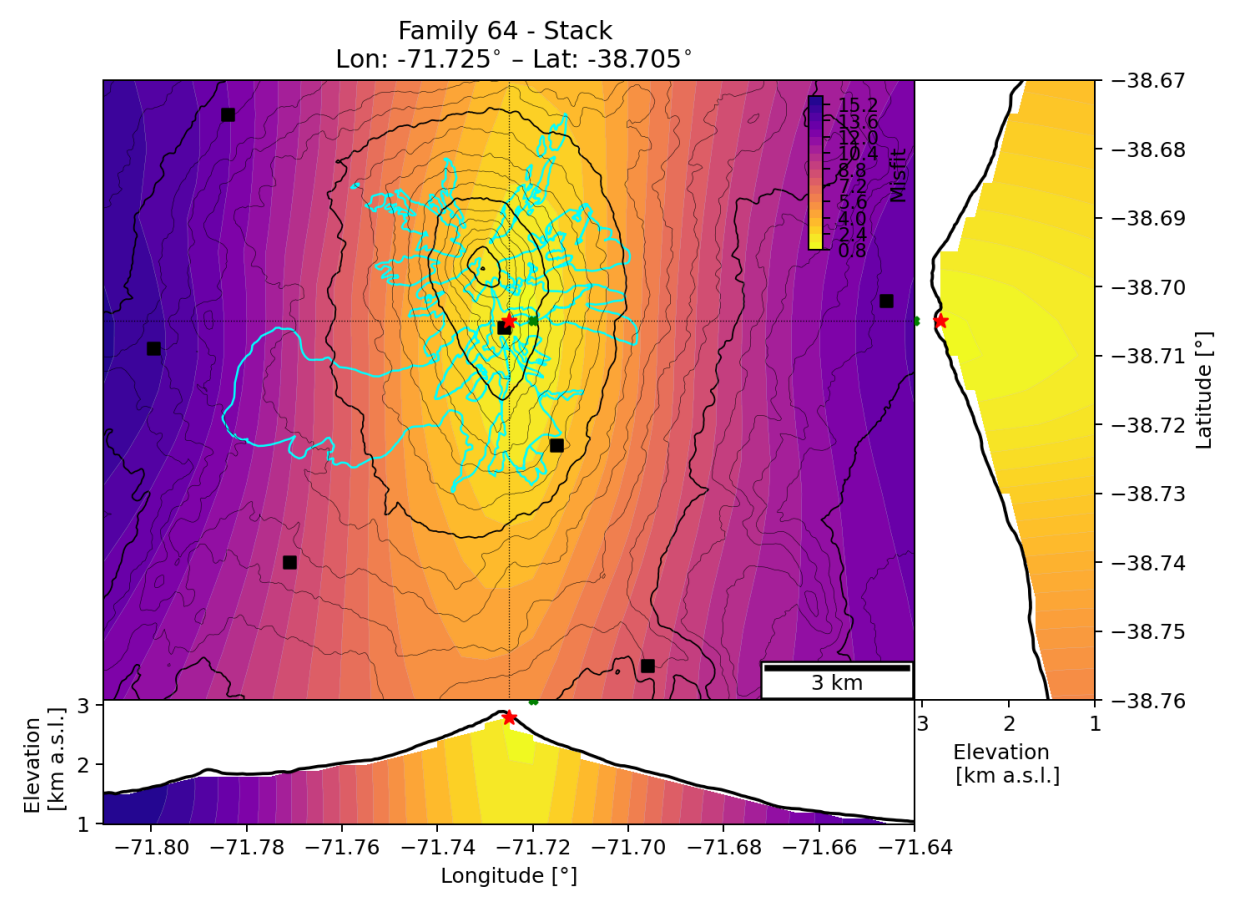

Figure S19. Location of Family 64. See caption of Fig. S5 for details.

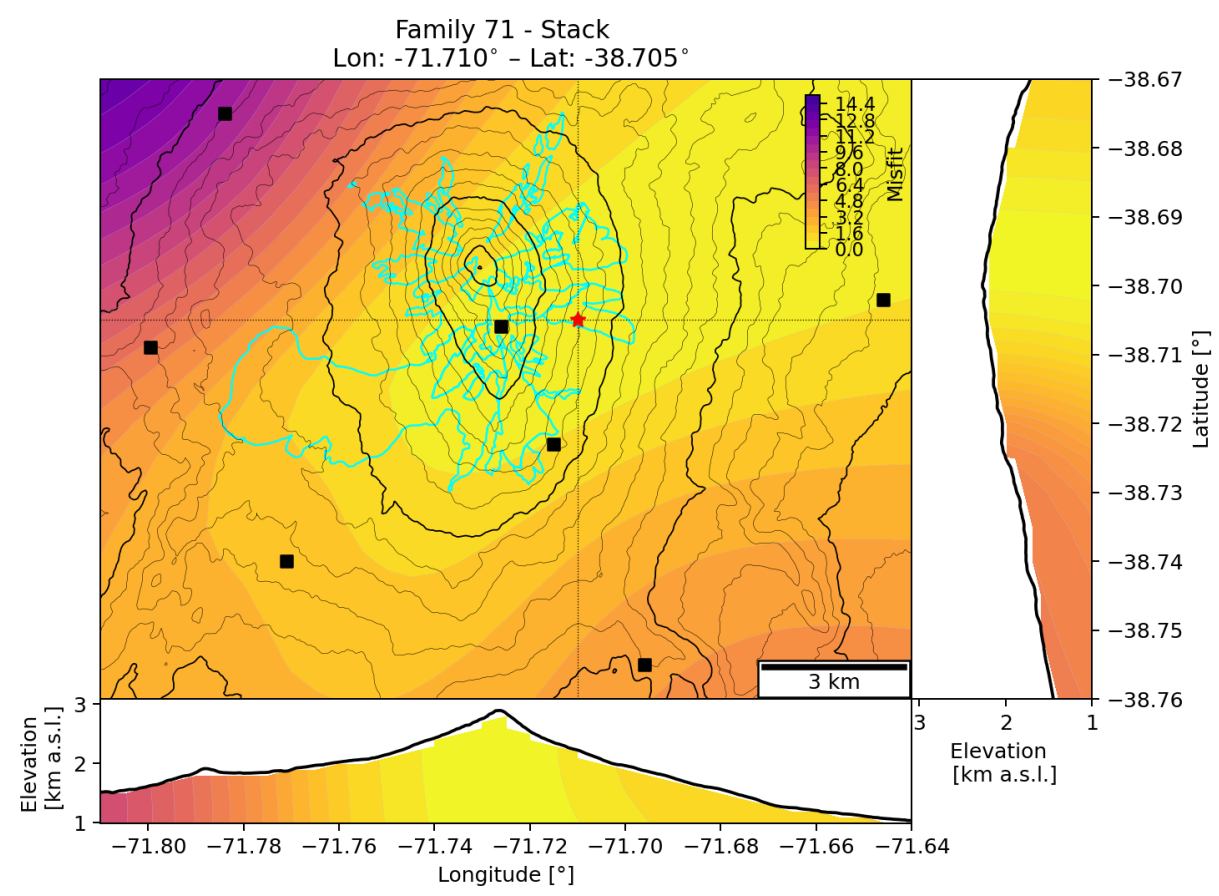

Figure S20. Location of Family 71. See caption of Fig. S5 for details. 


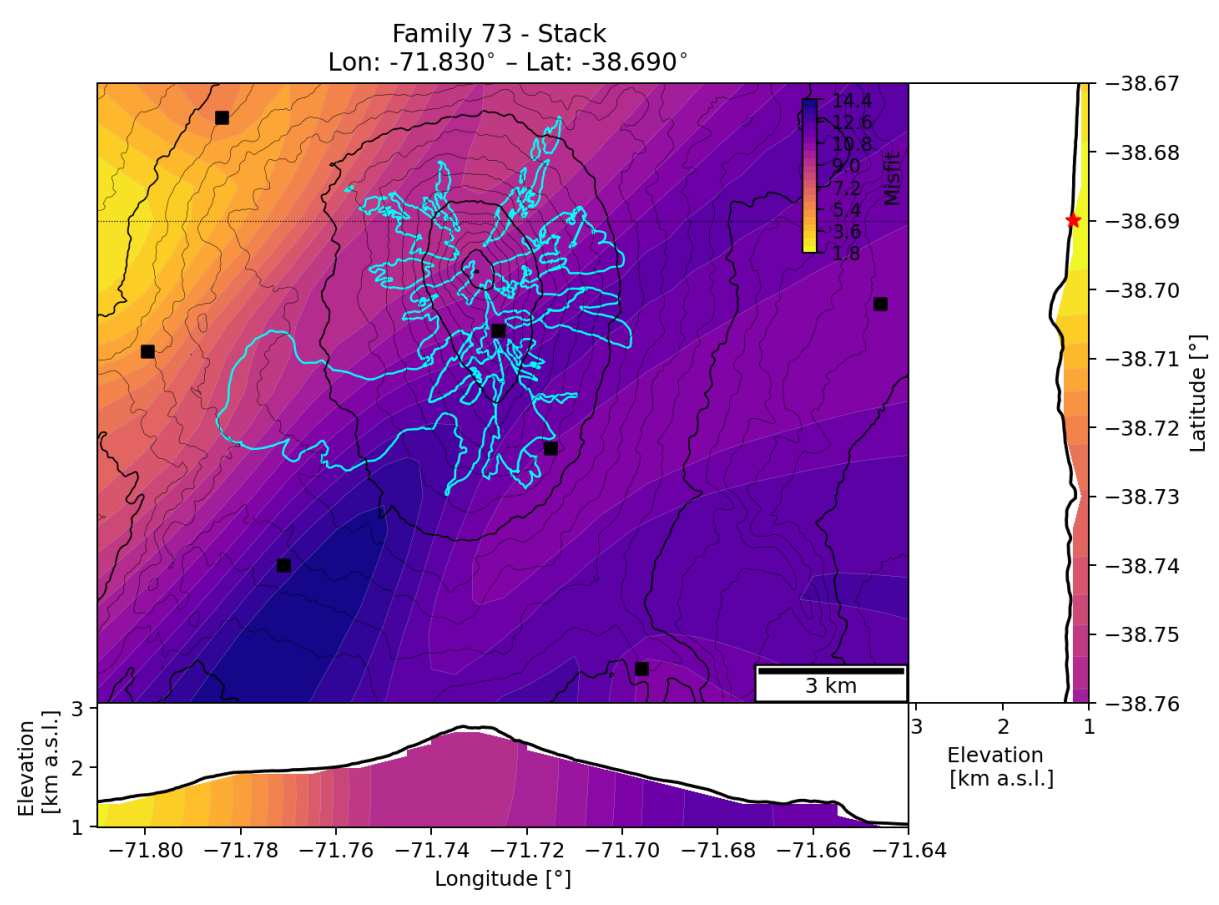

Figure S21. Location of Family 73, which was too close to edge to be considered. See caption of Fig. S5 for details. 